\title{
Modulating the Biological Function of Protein by Tailoring the Adsorption Orientation on Nanoparticles
}

Akhil Jain, Gustavo F. Trindade, Jacqueline M. Hicks, Jordan C. Potts, Ruman Rahman, Richard J. M. Hague, David B. Amabilino, Lluïsa Pérez-García, and Frankie J. Rawson*

Dr. Akhil Jain, Dr. Jacqueline M. Hicks, Dr. Frankie J. Rawson*

Division of Regenerative Medicine and Cellular Therapies

School of Pharmacy, University of Nottingham

Nottingham NG7 2RD, UK

*E-mail: Frankie.Rawson@nottingham.ac.uk

Dr. Gustavo F. Trindade, Jordan C. Potts and Dr. Lluïsa Pérez-García

Division of Advanced Materials and Healthcare Technologies

School of Pharmacy, University of Nottingham

Nottingham NG7 2RD, UK

Dr. Ruman Rahman

Children's Brain Tumour Research Centre

School of Medicine, University of Nottingham

Nottingham NG7 2UH, UK

Prof. Richard J. M. Hague

Centre for Additive Manufacturing

Faculty of Engineering, University of Nottingham

Nottingham NG8 1BB, UK

Prof. David B. Amabilino

GSK Carbon Neutral Laboratories for Sustainable Chemistry

School of Chemistry, University of Nottingham

Nottingham NG7 2TU, UK 
Protein orientation in nanoparticle-protein conjugates plays a crucial role in binding to cell receptors and ultimately, defines their targeting efficiency. Therefore, understanding fundamental aspects of the role of protein orientation upon adsorption on the surface of nanoparticles (NPs) is vital for the development of clinically important protein-based nanomedicine. In this work, new insights on the effect of the different orientation of cytochrome $c$ (cyt $c$ ) bound to gold nanoparticles (GNPs) using various ligands on its apoptotic activity is reported. Time-of-Flight Secondary-Ion Mass Spectrometry (ToFSIMS), electrochemical and circular dichroism (CD) analyses are used to investigate the characteristics of cyt $c$ orientation and structure on functionalized GNPs. These studies indicate that the orientation and position of the heme ring inside the cyt $c$ structure can be altered by changing the surface chemistry on the NPs. A difference in the apoptosis inducing capability because of different orientation of cyt $c$ bound to the GNPs is observed. These findings indicate that the biological activity of a protein can be modulated on the surface of NPs by varying its adsorption orientation. This study will impact on the rational design of new nanoscale biosensors, bioelectronics, and nanoparticle-protein based drugs.

\section{Introduction}

Our ability to tailor surfaces at the nanoscale for biomedical and biotechnological applications is expanding at an ever-greater pace. ${ }^{[1]}$ A key component of this field is the development of protein functionalized NPs. ${ }^{[2]}$ The advancement of NP-protein conjugates for sensing, imaging, drug delivery and targeting is of interest for many diverse applications. ${ }^{[3]}$ In particular, the NPprotein conjugates are regarded as new innovative therapeutic agents. ${ }^{[4]}$ Upon conjugation to NPs, therapeutic proteins can be delivered specifically at a desired targeted site. ${ }^{[5]}$ One such protein is cyt $c$, that has attracted special attention because of its dual role as an electron carrier in mitochondrial electron transfer chain (ETC) and as an initiator of apoptosis. ${ }^{[6]}$ Both these properties of cyt $c$ arise from the presence of a redox-active heme moiety embedded in its structure. ${ }^{[7]}$ Under apoptotic stimuli, cyt $c$ translocate to the cytosol by gaining peroxidase 
activity thus causing the oxidation of $\mathrm{Fe}^{2+}$ (inactive form) of the heme moiety to $\mathrm{Fe}^{3+}$ (active form) ${ }^{[8]}$ Upon reaching the cytosol this activated form of cyt $c$ triggers the apoptosis cascade. ${ }^{[6 a]}$ Therefore, in tumor cells where apoptosis rarely occurs (a hallmark of cancer), introduction of cyt $c$ could initiate the destruction of malignant cells. ${ }^{[9]}$ However, intracellular delivery of cyt $c$ is challenging because of its size $(\sim 3.1 \mathrm{~nm})$ and non-lipophilic nature. ${ }^{[10]}$ In order to address this delivery issue, mesoporous silica, lipid and hybrid NPs have been explored as delivery vehicles to enhance intracellular transport of cyt $c .{ }^{[11]}$ There is however a lack of understanding on how to control and manipulate the protein structure and its orientation-dependent properties to tailor the biological effects of NP-protein conjugates. Therefore, conceptualizing the fundamental aspects of cyt $c$ adsorption on NPs is important for predicting the impact of NPcyt $c$ conjugates on biological process, such as apoptosis.

The physicochemical properties of NPs have been shown to distort protein tertiary structure, which can perturb protein function. ${ }^{[12]}$ To this end, studies have been conducted to identify the labelling/ binding site of the cyt $c$ on NPs. ${ }^{[13]}$ Other factors such as NP size and charge have been identified to influence the structure of cyt $c$ and thus its electron transfer and peroxidase activity. ${ }^{[14]}$ Protein orientation has also been shown to play a crucial role in its targeting ability. ${ }^{[15]}$ However, in the case of cyt $c$, most of the investigations on determining its orientation have been limited to macro-sized flat surfaces rather than curved NP surfaces bearing different charge, which hinders its application at a cellular level. ${ }^{[16]}$ Recently, Tollefson et al. inferred the orientation of cyt $c$ on anionic ligand (mercaptopropionic acid) functionalized GNPs by using both molecular dynamics simulation and experimental approach. ${ }^{[17]}$ Importantly, none of the above-mentioned studies determined the orientation-dependent biological activity of cyt $c$. Therefore, we envisaged that for redox-active and therapeutically important proteins such as cyt $c$, the orientation of heme moiety with respect to NP surface could play an important role in determining its activity. 
To the best of our knowledge, no studies have appraised the ability of cyt $c$ to instigate apoptosis when modulating its conformation and orientation on the surface of NPs. Therefore, the aim of this work was to tailor the surface chemistry of the GNPs to modulate the orientation and conformation of cyt $c$. Subsequently, we wanted to establish the effect of these structural and orientation changes on the bioactivity of cyt $c$. In order to do this, we have used GNP-cyt $c$ nanoconjugates to analyze and relate the orientation of cyt $c$ to its apoptotic activity. We have shown that electrostatic interactions between GNPs with different surface charge can induce different orientation of bound cyt $c$ (Figure 1a). We have further detailed the changes in the cyt $c$ secondary and tertiary structures caused by the charged ligands on GNPs (Figure 1b). Changes in the redox kinetics of cyt $c$ arising from different orientations of the protein on GNPs were examined by electrochemical measurements (Figure 1c). Finally, we have assessed the effect of different orientation and change in cyt $c$ structure on its apoptotic and peroxidase activity (Figure 1d). Based on the obtained results, we propose a general guideline that both protein structure and orientation on the surface of NPs should be considered, assessed and accounted when modulating biological activity.

\section{Results and Discussions}

\subsection{Synthesis and characterization of GNP.cyt c nanoconjugates: GNP-protein conjugates} have become a popular choice in nanomedicine and sensing applications because of the physicochemical properties of GNPs, such as ease of surface modification, surface plasmon resonance (SPR), stability and biocompatibility. ${ }^{[18]}$ Therefore, we set out to customize the surface chemistry of GNPs where we hypothesized that this would aid in modulating cyt $c$ orientation and conformation. The synthesis of GNP.cyt $c$ conjugates was accomplished by first generating three different sets of GNPs coated with either cationic, anionic, or neutral ligands of identical molecular weight (2000 Da) under physiological conditions for cyt $c$ binding. The citrate-capped GNPs were named GNP.COOH, GNP.NH 2 , and GNP.OH upon functionalization with thiol-PEG-carboxylic acid, thiol-PEG-amine, and thiol-PEG-hydroxyl, 
respectively. Later, cyt $c$ was adsorbed on these PEGylated GNPs upon incubation for $24 \mathrm{~h}$, which was followed by multiple washing to remove any unbound protein. The obtained GNP.cyt $c$ conjugates were named GNP.COOH.cyt $c$, GNP.NH2.cyt $c$, and GNP.OH.cyt $c$ (Figure 1a).

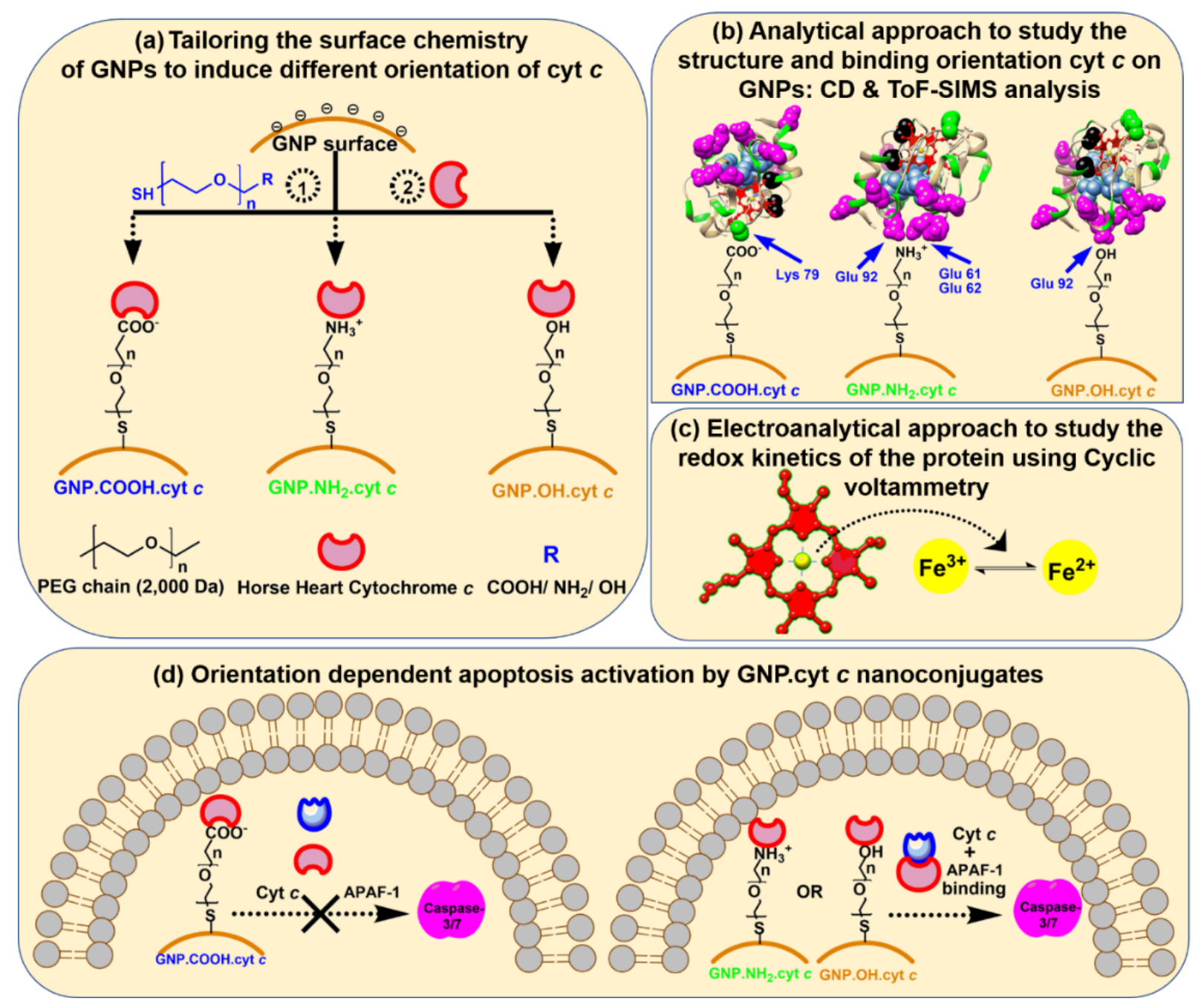

Figure 1. Schematic representation of the experimental approach followed to investigate the orientation dependent apoptotic activity of cyt $c$ bound GNPs. (a) Surface functionalization of citrate-capped GNPs with anionic, cationic and neutral ligands to modulate the orientation of cyt $c$. (b) Analytical approach to identify the structure and orientation of cyt $c$ on GNPs. Proposed model for the adsorption orientation and interaction site of cyt $c$ on GNPs with three different ligands. The crystal structure of horse heart cyt $c$ was obtained from PDB (1 HRC) and University of California, San Francisco (UCSF) Chimera (version $1.14 \mathrm{rc}$ ) was used to label 
amino acid residues and heme ring. In cyt $c$ structure - red: heme/porphyrin ring; black: cysteine (Cys); magenta: glutamic acid (Glu); blue: leucine (Leu); green: lysine (Lys); and yellow: Iron (Fe). (c) Electroanalytical approach to study the redox kinetics of cyt $c$ bound to GNPs. (d) In vitro cell culture studies to analyze the capability of cyt $c$ bound GNPs to activate Caspase-3/7. Cyt $c$ consists of positively charged Lysine (Lys) residues that are distributed across the protein and negatively charged glutamic acid residues on the other side near to the heme moiety in the protein structure. ${ }^{[19]}$ We expected that cyt $c$ would have a different orientation on GNPs functionalized with different ligands resulting from electrostatic interactions. TEM measurements revealed that the mean diameter of different GNP.cyt $c$ conjugates is between 130-133 nm (Figure 2a-c). The UV-Vis absorption spectrum of free cyt $c$ exhibited the Soret band at $\lambda_{\max }=409 \mathrm{~nm}$ and another peak centered at $525 \mathrm{~nm}$ corresponding to the $\mathrm{Q}$ band. The presence of this single $\mathrm{Q}$ band has been attributed to the oxidized form of cyt $c .{ }^{[20]}$ The absorption spectrum of citrate-capped GNPs showed a characteristic surface plasmon resonance (SPR) peak at $\lambda_{\max }=569 \mathrm{~nm}$. After cyt $c$ binding all the samples showed peaks corresponding to the Soret band of cyt $c$ at $\lambda_{\max }=409 \mathrm{~nm}$ and a slightly red-shifted SPR band at $\lambda_{\max }=572$ nm (Figure 2d). By using the UV-Vis absorption spectra and extinction coefficient of GNPs and cyt $c$, the number of cyt $c$ molecules attached to single GNP was estimated (Table S1). According to the surface area of a sphere $\left(4 \pi r^{2}\right)$, the calculated area of a single PEGylated GNP $(\mathrm{d}=\sim 134 \mathrm{~nm})$ and a single cyt $c$ molecule $(\mathrm{d}=\sim 3.4 \mathrm{~nm})$ is $\sim 5.64 \times 10^{4} \mathrm{~nm}^{2}$ and $\sim 36.32 \mathrm{~nm}^{2}$, respectively. Therefore, the theoretical coverage of cyt $c$ on PEGylated GNPs should be $\sim 1550$ cyt $c$ GNP. Since, the particles are monodispersed as suggested by TEM and polydispersity index, the total surface of PEGylated GNPs (n) can be obtained by multiplying the total number of PEGylated GNPs in each sample (obtained using UV-Vis data, see Table S1) with the area of a single PEGylated GNP. The calculated total surface area of GNP.COOH, GNP.NH2, and GNP.OH samples that were incubated with cyt $c$ at a concentration of either 100, 150, or 150 $\mu \mathrm{M}$, respectively, was $2.03 \times 10^{13}, 1.97 \times 10^{13}$, and $1.46 \times 10^{13}$. Likewise, the calculated total 
surface area of cyt $c$ bound to the GNP.COOH, GNP.NH2, and GNP.OH samples was $2.09 \times$ $10^{16}, 2.03 \times 10^{16}$ and $1.48 \times 10^{16}$, respectively. Therefore, the calculated number of cyt $c$ molecules on a single GNP.COOH, GNP.NH2, and GNP.OH nanoparticle was $\sim 1029, \sim 1030$, $\sim 1013$, respectively, with the average cyt $c$ coverage on a single PEGylated GNPs was $\sim 70 \%$ of the theoretical value. Particularly, these analyses indicate that a similar number of cyt $c$ /GNP $\left(\sim 10^{3}\right.$ cyt $c$ molecules/GNP) was achieved in this work, when GNP.COOH, GNP.NH 2 , and GNP.OH were incubated with cyt $c$ at a concentration of either 100,150 , or $150 \mu \mathrm{M}$, respectively. XPS analyses was further conducted to confirm if a similar concentration of cyt $c$ is bound to GNPs with different ligands using the atomic percentage (at. \%) of N. The analyses revealed that GNP.COOH, GNP.NH $\mathrm{NH}_{2}$, and GNP.OH samples have a similar amount of N (at. \%) (Table S2). The XPS quantification analyses is consistent with UV-Vis data, thus confirming that indeed similar number of cyt c/GNP were obtained. Dynamic light scattering (DLS) analyses revealed an increase in the hydrodynamic diameter of GNPs after surface modification with the ligand and cyt $c$ (Figure 2e). As expected, the $\zeta$ data indicates that GNPs with different surface charges were obtained after functionalization with different heterobifunctional PEG ligands (Figure 2f). The $\zeta$ values of ligands-functionalized GNPs changed significantly to positive after cyt $c$ binding, which could be a result of an overall positive charge of cyt $c .^{[21]}$ Furthermore, GNP.COOH.cyt $c$, GNP.NH2.cyt $c$, and GNP.OH.cyt $c$ displayed a polydispersity index (PDI) of $0.13,0.11$, and 0.09 , indicating that the samples are very homogeneous. 

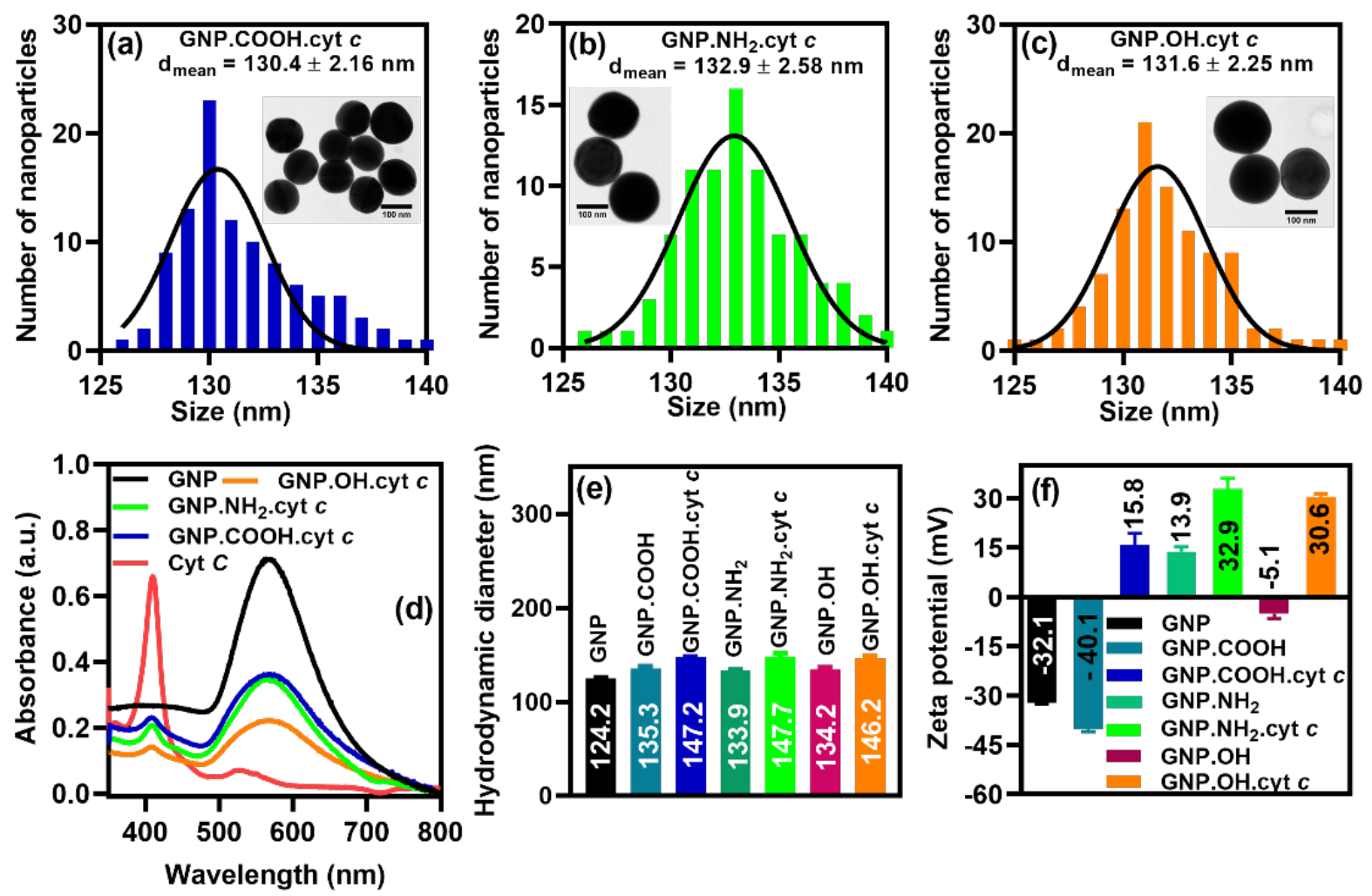

Figure 2. Physicochemical characterization of cyt $c$ bound GNPs using three different ligands.

( $a, b$ and $c$ ) Histogram of the particle size distribution of cyt $c$ bound GNPs using cationic (GNP.COOH), anionic (GNP.NH 2 ) and neutral ligand (GNP.OH), respectively. Inset shows the representative TEM image. (d) UV-Vis absorption spectrum; (e) Hydrodynamic diameter analyzed using DLS and (f) Zeta potential of unmodified citrate-capped gold nanoparticles (GNPs) and surface-modified GNPs. The error bars represent the S.E.M of the average value obtained after measurements from three different preparation of GNPs.

\subsection{Analytical approach to determine the structure, conformation and orientation of cyt con}

GNPs: Circular dichroism (CD) spectroscopy was utilized to investigate the structure of cyt $c$ bound to GNPs. In a UV CD spectrum (200 - $260 \mathrm{~nm})$, molecular ellipticity at 208 and $222 \mathrm{~nm}$ represent the $\alpha$ helical content and catalytical activity of the protein $;^{[22]}$ in this work, all the samples including native cyt $c$ showed two double minima at 208 and $222 \mathrm{~nm}$. A slight loss and improvement in the helicity of cyt $c$ bound to GNP.COOH and GNP.OH, respectively (Figure 3a) was observed. However, all the samples showed similar pattern and molecular ellipticity to 
that of native cyt $c$. Therefore, these results suggest that cyt $c$ retains its native secondary structure on GNPs with different ligands.

The UV CD spectra of native cyt $c$ in the range $260-360 \mathrm{~nm}$ showed (Figure 3b) two minima at 282 and $288 \mathrm{~nm}$ attributed to the tertiary structure of Tryptophan (Trp) residues. ${ }^{[23]}$ In GNP.COOH.cyt $c$, the blue shift in one of the minima to $278 \mathrm{~nm}$ indicates that the tertiary structure is perturbed compared with the native cyt $c$. On the other hand, GNP.NH. cyt $c$ and GNP.OH.cyt $c$ samples showed almost identical Trp minima as native cyt $c$, indicating that the tertiary structure of cyt $c$ remains unchanged.

Further insight on the tertiary structure of the amino acid residues near to the heme ring was obtained by monitoring the Soret region $(360-450 \mathrm{~nm})$ of the CD spectra. The Soret CD

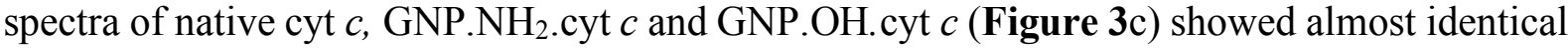
spectra with two positive maxima (406 and $397 \mathrm{~nm}$ ) and one negative minimum (419 $\mathrm{nm}$ ) indicating no structural perturbation around the heme moiety. However, for the GNP.COOH.cyt $c$ samples, the negative minimum red-shifted to $423 \mathrm{~nm}$ and an increase in molecular ellipticity of the positive peaks were observed, indicating slight perturbation in cyt $c$ structure in the vicinity of heme ring. Overall, the $\mathrm{CD}$ analysis revealed that cyt $c$ retains its secondary structure in all the samples irrespective of the charge of the ligands. However, the tertiary structure of cyt $c$ is distorted in the GNPs functionalized with an anionic ligand, which could be a result of a strong electrostatic interaction between the carboxylate groups and positively charged amino acid residues adjacent to the heme ring. 

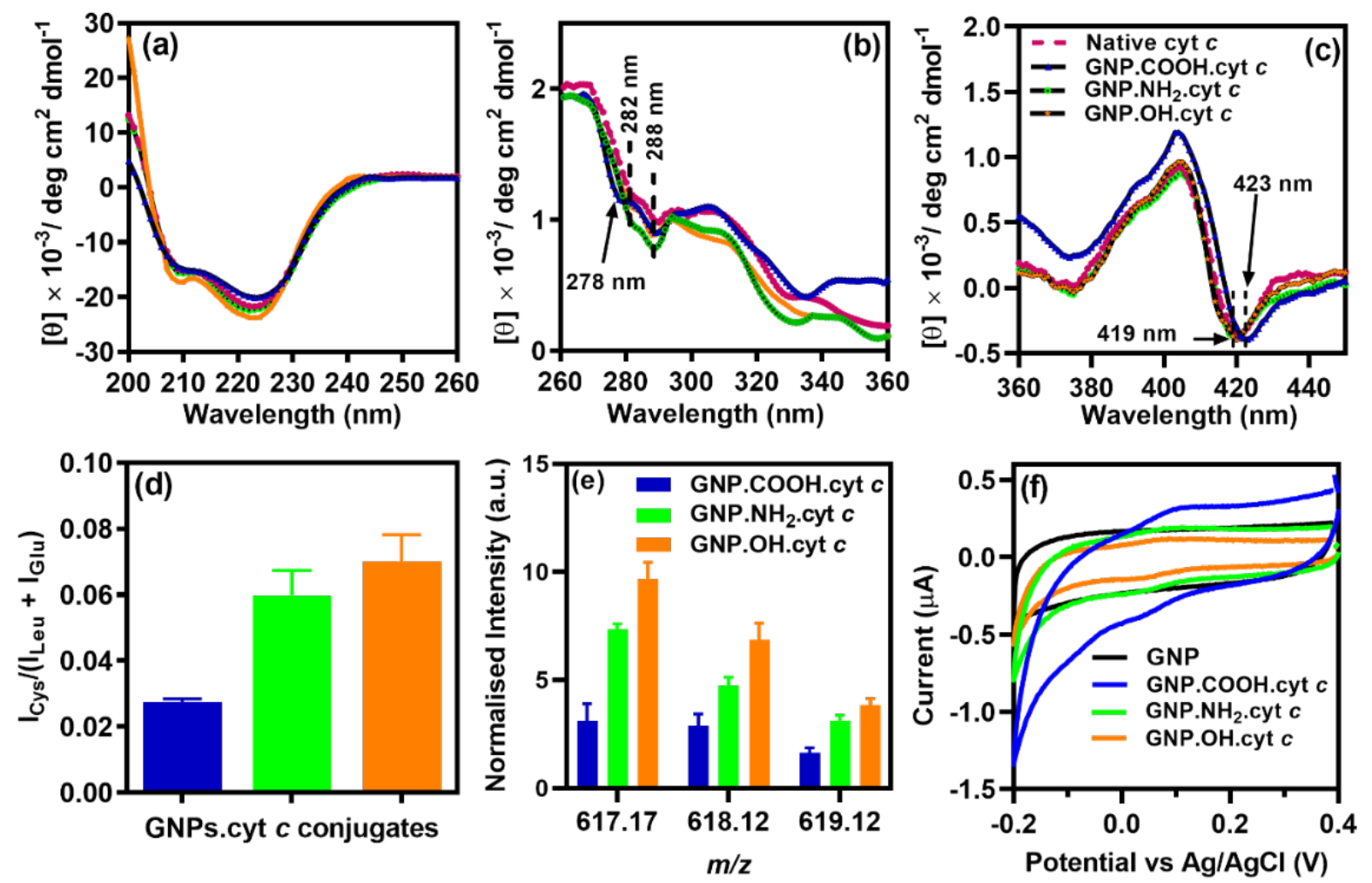

Figure 3. Structure and orientation of cyt $c$ bound to GNPs. (a) Far-UV CD; (b) near-UV CD; and (c) Soret CD spectrum of free native cyt $c$ and cyt $c$ bound to GNPs in $10 \mathrm{mM}$ PBS $(\mathrm{pH}=$ 7.4). All samples with identical concentration $(25 \mu \mathrm{g} / \mathrm{mL})$ were used for spectrum acquisition. Three spectra of each sample were collected and averaged. (d) ToF-SIMS peak intensity ratio, represented as the sum of intensities from cysteine/glumatic acid + leucine for cyt $c$ bound GNP samples. (e) ToF-SIMS peak intensities for cyt $c$ heme ring fragment. Error bars represent the standard deviation across six different analysis spots. (f) Comparative cyclic voltammograms (CVs) of GNPs with different orientations of cyt $c$. A scan rate of $100 \mathrm{mV} \cdot \mathrm{s}^{-1}$. Redox potentials measured using an Indium tin oxide (ITO) working electrode with different samples dispersed in PBS. Similar colors have been used in (a)-(c) and (d)- (e) to represent the samples.

ToF-SIMS was used to probe the orientation of cyt $c$ when bound to GNPs. The approach followed takes advantage of the extremely high surface sensitivity of ToF-SIMS to correlate changes in the secondary ion intensity related to cysteine residues $\left(\mathrm{Cys}: \mathrm{C}_{2} \mathrm{H}_{6} \mathrm{NS}^{+}\right.$$76.015 \mathrm{u})$ that exist next to the heme moiety, and glutamic acid (Glu: $\mathrm{C}_{6} \mathrm{H}_{6} \mathrm{NO}^{+}-84.053 \mathrm{u}$ and $\mathrm{C}_{4} \mathrm{H}_{8} \mathrm{NO}_{2}{ }^{+}-102.046 \mathrm{u}$ ) and leucine (Leu: $\mathrm{C}_{5} \mathrm{H}_{12} \mathrm{~N}^{+}-86.09 \mathrm{u}$ ) rich region at the opposite end of 
the heme region, to changes in protein orientation. Therefore, the ratio $\mathrm{R}=\mathrm{I}_{\mathrm{Cys}} /\left(\mathrm{I}_{\mathrm{Leu}}+\mathrm{I}_{\mathrm{Glu}}\right)$ for cyt $c$ bound GNP samples with three different ligands can be used as a probe to determine cyt $c$ orientation. ${ }^{[24]}$ The analysis revealed nearly $50 \%$ difference in $\mathrm{R}$ values between GNP.COOH.cyt $c$ and GNP.OH.cyt $c$ or GNP.NH 2 cyt $c$ (Figure 3d), where a similar ratio has been reported earlier in an approach previously established for flat gold surfaces. ${ }^{[24]}$ The obtained data provides significant pieces of evidences that suggest the different orientation of cyt $c$ on GNPs with the different ligands. Therefore, we hypothesized that in GNP.COOH.cyt $c$ samples the Cys residues must be located near to the ligand-protein interface, thus explaining the lower value of R and vice-versa for Glu or Leu residues (protein-medium interface). On the other hand, the higher R values for the GNP.OH.cyt $c$ and GNP.NH $\mathrm{NH}_{2}$ cyt $c$ samples indicate that the Glu and Leu residues are near to the ligand surface. To support this hypothesis, we analyzed the secondary ion intensity from the heme moiety consisting an iron-porphyrin fragments $\left(\mathrm{C}_{34} \mathrm{H}_{33} \mathrm{~N}_{4} \mathrm{O}_{4} \mathrm{Fe}^{+}-617.186 \mathrm{u}, 618.12 \mathrm{u}\right.$ and $\left.619.12 \mathrm{u}\right)$ (Figure 3e and Figure $\left.\mathrm{S} 1\right)$. The obtained results agree with the observed differences in $\mathrm{R}$ values, indicating that the position of heme group changes because of different cyt $c$ orientation induced by different ligands and accepts the hypothesis. The ToF-SIMS data reported in this work suggest only the average orientation of cyt $c$ on GNPs i.e. the most preferred orientation or the orientation that is adopted by cyt $c$ on a greater number of GNPs ${ }^{[17]}$

By carefully analyzing the crystal structure of cyt $c$ (Horse heart; PDB entry 1 HRC), $\mathrm{CD}$ and ToF-SIMS data, we propose the adsorption orientation of cyt $c$ bound to GNPs using different ligands (Figure 1b). In GNP.COOH.cyt $c$ sample, cyt $c$ adopts an orientation wherein the heme ring is buried near to the protein-ligand interface with positively charged Lys79 residues interacting with carboxylate groups of the ligand through electrostatic interaction. Such an orientation results in Cys residues near to the carboxylic group of the ligand thus causing the disruption of thioester linkage and thus justify the observed perturbation in the tertiary structure of cyt $c$ (observed in CD spectrum) on GNP.COOH.cyt $c$ samples. Similar 
orientation of cyt $c$ was reported by Lin et al. on 11-mercaptoundecanoic acid-modified gold electrodes. ${ }^{[16 b]}$ In GNP.NH $2 . c y t ~ c$ and GNP.OH.cyt $c$ samples, cyt $c$ adopts an orientation opposite to GNP.COOH.cyt $c$ samples, with the heme cleft exposed to the top of the surface and near to the protein-medium interface. This orientation results in negatively charged Glu 61 , $\mathrm{Glu}_{62}$, and $\mathrm{Glu}_{92}$ residues near to the amine groups and $\mathrm{Glu}_{92}$ residues near to the hydroxyl group of the ligands suggesting that the nature of interaction could be ionic or hydrogen bonding.

We also established the effect of tuning the molecular conformation and orientation of cyt $c$ on its redox properties. We performed cyclic voltammetry (CV) analyses of the different GNP.cyt $c$ conjugates at $100 \mathrm{mV} \cdot \mathrm{s}^{-1}$. We also conducted a scan rate study over the range of 50 $\mathrm{mV} . \mathrm{s}^{-1}$ to $2 \mathrm{~V} . \mathrm{s}^{-1}$ (Figure S2 a-c). A redox couple was observed for the cyt $c$ bound GNP samples that was not present in the unmodified GNP control (Figure 3f). The presence of these redox peaks at $\sim 0.09 \mathrm{~V}$ (oxidation peak) and $\sim 0.039 \mathrm{~V}$ (reduction peak) has been attributed to the redox nature of $\mathrm{Fe}$ center embedded in the heme ring of cyt $c .{ }^{[25]}$ Notably, the observed redox couple is only because of cyt $c$ bound to GNPs, as the peaks originating from protonation and deprotonation of the surface reactive groups (carboxylic, amine, hydroxyl and thiols) does not coincide with the redox peaks reported in this work. ${ }^{[26]}$ Peak separation recorded at the 100 $\mathrm{mV} . \mathrm{s}^{-1}$ scan rate was $69 \mathrm{mV}, 76 \mathrm{mV}$ and $65 \mathrm{mV}$ for the GNP.COOH.cyt $c$, GNP.NH $2 . c y t c$ and GNP.OH.cyt $c$ samples, respectively. On analyzing the scan rate study, a proportional relationship was seen when plotting peak current vs scan rate (Figure S2 d-f). These important observations are indicative of a surface-bound electrochemical process and supports our assertion of the proposed surface modification and suggests that the surface chemistry is stable. This is further supported by the fact that there is no significant difference in peak reducing current measured after 100 consecutive scan rates (Figure S2 g-i); this shows that the functionalized nanoparticles are electrochemically stable and there is no observed dissociation of surface bound ligands. As peak current is proportional to concentration of Cyt $\mathrm{c}$ this also shows the stability of the surface chemistry. If the cyt $\mathrm{c}$ was dissociating due to ligand 
instability the peak current associated with Cyt c would become smaller. Most interesting though is when the formal electrode potential was calculated, where we observed values of 126 $\mathrm{mV}, 112 \mathrm{mV}$ and $116 \mathrm{mV}$ for GNP.COOH.cyt $c$, GNP.NH $\mathrm{N}_{2} . c y t ~ c$ and GNP.OH.cyt $c$, respectively; this observed difference in the values of formal electrode potential indicates that the ratio of Fe oxidation states in the heme ring differs in cyt $c$ bound GNPs samples. This is important as the redox ratio of $\mathrm{Fe}$ within the cyt $c$ has been linked to its peroxidase activity which can possibly affect its apoptotic induction capability. ${ }^{[27]}$

\subsection{Orientation dependent apoptotic and peroxidase activity of GNP.cyt c nanoconjugates:}

Encouraged by our findings that cyt $c$ adopts different orientations on GNPs with different ligands, we wanted to establish an understanding of conformation and orientation effects on apoptotic activity of GNP.cyt $c$ conjugates. However, considering the possibility of cyt $c$ degradation by proteases under in vitro conditions, we first conducted a trypsin-based degradation assay, ${ }^{[28]}$ to examine the degradation of cyt $c$ bound to GNPs. We observed similar degradation kinetics for all the samples upon incubation with $4 \mathrm{mg} / \mathrm{mL}$ of trypsin (Figure 4a). Approximately $10 \%$ degradation of cyt $c$ was observed at 1 and $4 \mathrm{~h}$, however, as expected, after $8 \mathrm{~h}$, there was a significant increase in the degradation of cyt $c$ bound to GNPs. Nevertheless, for the cell-based experiments, we chose 1 and $4 \mathrm{~h}$ as the optimum time period to study the biological response of these GNPs because all the samples showed almost identical degradation of cyt $c$. We show that there is no significant degradation in the cytochrome response over the time frame of our experiments. This indicates the surface chemistry of nanoparticles is similar between the AuNP and the ligand differences is not impacting on the biological stability of the Cyt c. If ligand differences at the surface were impacting on the stability of cyt $\mathrm{c}$ we would expect the rate of degradation to be the different.

Next, we assessed the capability of cyt $c$ bound GNPs to induce apoptosis using a colorimetric assay that detects the activity of Caspase-3, which is upregulated during apoptosis. However, it has been reported earlier that cyt $c$ is a membrane-impermeable protein ${ }^{[29]}$ and it 
is thus critical to analyze the ability of cyt $c$ bound GNPs to activate Caspase- 3 in a cell-free system. Therefore, we first analyzed the Caspase-3 activation in freshly extracted cytosol from U251 malignant brain tumor cells upon incubation with native cyt $c$ and GNP.cyt $c$ conjugates for 1 and 4 h. As shown in Figure 4b, we observe a significantly higher ( $p$-value $<0.0001$ ) Caspase-3 activation in cytosol incubated with native cyt $c$, GNP.NH 2 .cyt $c$ or GNP.OH.cyt $c$ compared to GNP.COOH.cyt $c$. The observed difference in Caspase-3 activation between the different GNP.cyt $c$ conjugates could result only from the difference in their capability to interact with Apoptotic protease activating factor 1 (APAF-1), induced by the different orientation of cyt $c$ on GNPs.

Before testing this hypothesis in vitro, that the orientation of cyt $c$ governs its apoptotic activity, we studied the cellular uptake of the cyt $c$ and ligands functionalized GNPs in U251 cells using Inductively Coupled Plasma Mass Spectrometry (ICP-MS). ICP-MS analysis revealed that there was no significant difference in the uptake of cyt $c$ bound GNPs using different ligands at 1 and $4 \mathrm{~h}$ (Figure 4c). Interestingly, we found that cyt $c$ bound GNPs showed significantly less uptake compared to GNPs functionalized with ligands. This observed difference in the cellular uptake could be caused by the membrane-impermeability of cyt $c$. Nevertheless, the obtained data suggest similar level of association between the cells and different GNP.cyt $c$ conjugates. The results obtained in a cell-free system were validated by performing Caspase and metabolic assays in vitro. The Caspase-3 activation in U251 cells upon incubation with GNPs show that GNP.NH $2 . c y t ~ c$ and GNP.OH.cyt $c$ have the highest Caspase3 activation at 1 and $4 \mathrm{~h}$ ( $p$-value $<0.05$ vs GNP.COOH.cyt $c$ ), while native cyt $c$ and ligands functionalized GNPs show negligible Caspase-3 activation (Figure 4d). 

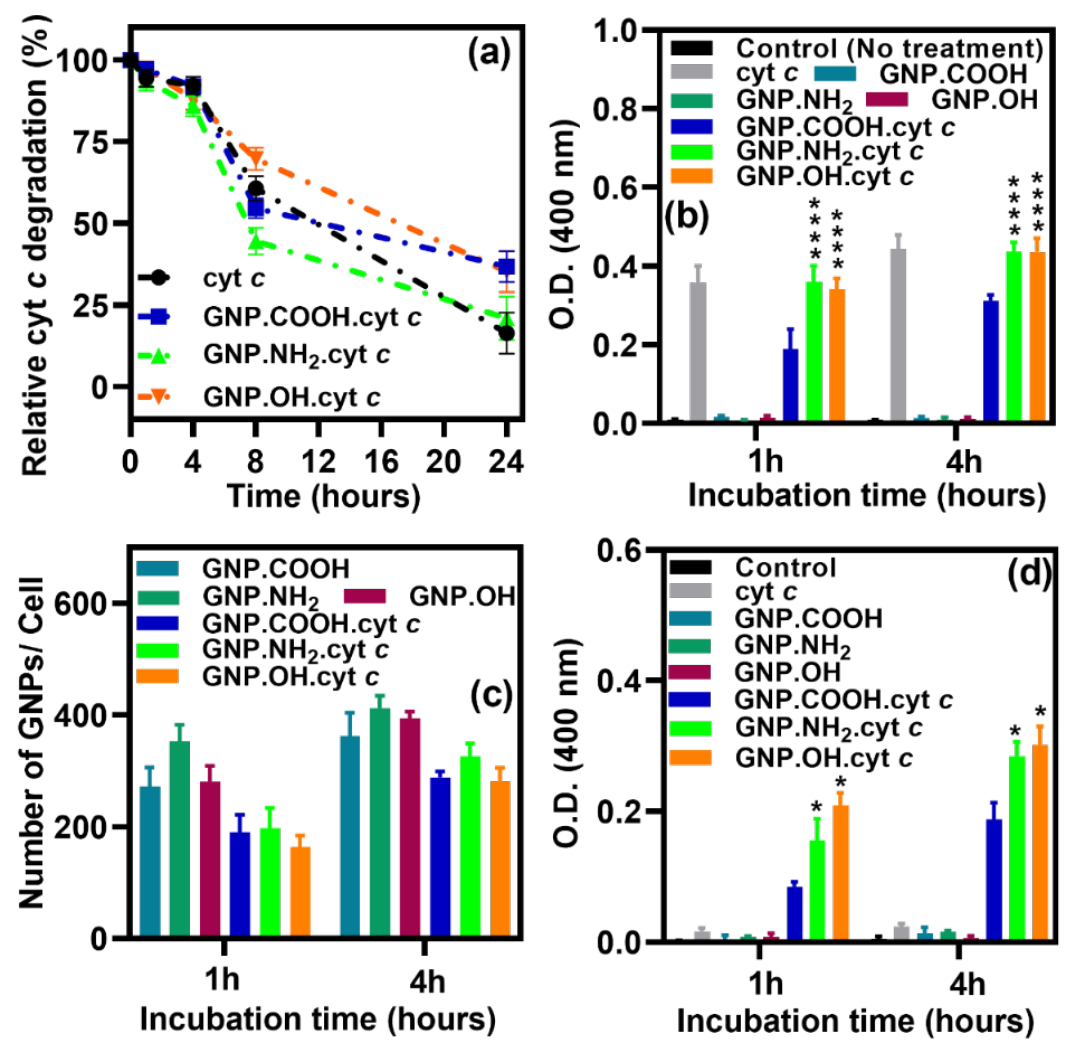

Figure 4. Orientation dependent apoptotic activity of cyt $c$ bound GNPs. (a) Degradation kinetics of free and GNPs bound cyt $c$ upon incubation with trypsin at $37^{\circ}$. (b) Cell-free colorimetric Caspase-3 activity assay to determine the capability of different GNP.cyt $c$ conjugates to induce apoptosis. (c) Cellular uptake of GNPs in U251 glioblastoma cells determing using ICP-MS, the data is expressed as the number of GNPs per cell. (d) In vitro Caspase-3 assay in U251 cells incubated with cyt $c$ bound GNPs for 1 and $4 \mathrm{~h}$. All the experiments were performed in triplicates and repeated for atleast 2-3 times. Results are expressed as mean \pm S.D. ${ }^{*} \mathrm{P}<0.05 ; * * * * \mathrm{P}<0.0001$ vs GNP.COOH.cyt $c$, obtained using 2way ANOVA with a Tukey post-test.

We further confirmed these results by conducting a fluorescence-based Caspase-3/7 assay. Figure 5 a-c show the confocal microscopy images of U251 cells treated with cyt $c$ bound GNP samples. The presence of green color arises from the activation of Caspase-3/7 was $\sim 50 \%$ higher in cells treated with GNP.NH $\mathrm{NH}_{2}$.cyt $c$ or GNP.OH.cyt $c$ compared to GNP.COOH.cyt $c$ (Figure 5d). On the other hand, the GNPs functionalized only with ligands 
(no cyt $c$ ) and free native cyt $c$ do not elicit any Caspase activation (Figure S3 a-e). These in vitro results are consistent with our studies in a cell-free system, thereby supporting our hypothesis. Therefore, based on the obtained results, we believe that the difference in Caspase3 activation by GNPs is because of the orientation of cyt $c$ induced by the surface charge of the ligands. Furthermore, it is worth mentioning that the observed effect is not due to different levels of association between GNP.cyt $c$ conjugates and the cells, otherwise we would have observed a significant difference in the cellular uptake of different GNP.cyt c conjugates and conversely in the apoptosis inducing capability of GNP.cyt c conjugates in a cell-free system. The cationic and neutral ligands permit cyt $c$ to adopt an orientation in which the heme cleft is exposed and accessible for establishing interaction with the WD-40 domain of APAF-1, thus initiating the apoptosis cascade eventually leading to Caspase-3 activation. ${ }^{[30]}$

The successful Caspase-3 activation induced by cyt $c$ bound GNPs allowed us to further study their effect on the metabolic activity of U251 cells. No significant change in the metabolic acivity of U251 cells is observed upon incubation with different GNP.cyt $c$ conjugates at lower concentration $(12.5 \mu \mathrm{g} / \mathrm{mL})$. A $20 \%$ decrease in cell metabolism was observed after $4 \mathrm{~h}$ of incubation with different GNP.cyt $c$ conjugates at a higher concentration $(25 \mu \mathrm{g} / \mathrm{mL})$. Statistical analysis revealed that the observed decrease in the viability is significant (GNP.COOH.cyt $c$ vs GNP.NH $\mathrm{NH}_{2}$.cyt $c$ or GNP.OH.cyt $c ; p$-value $<0.01$ ) (Figure S4). 

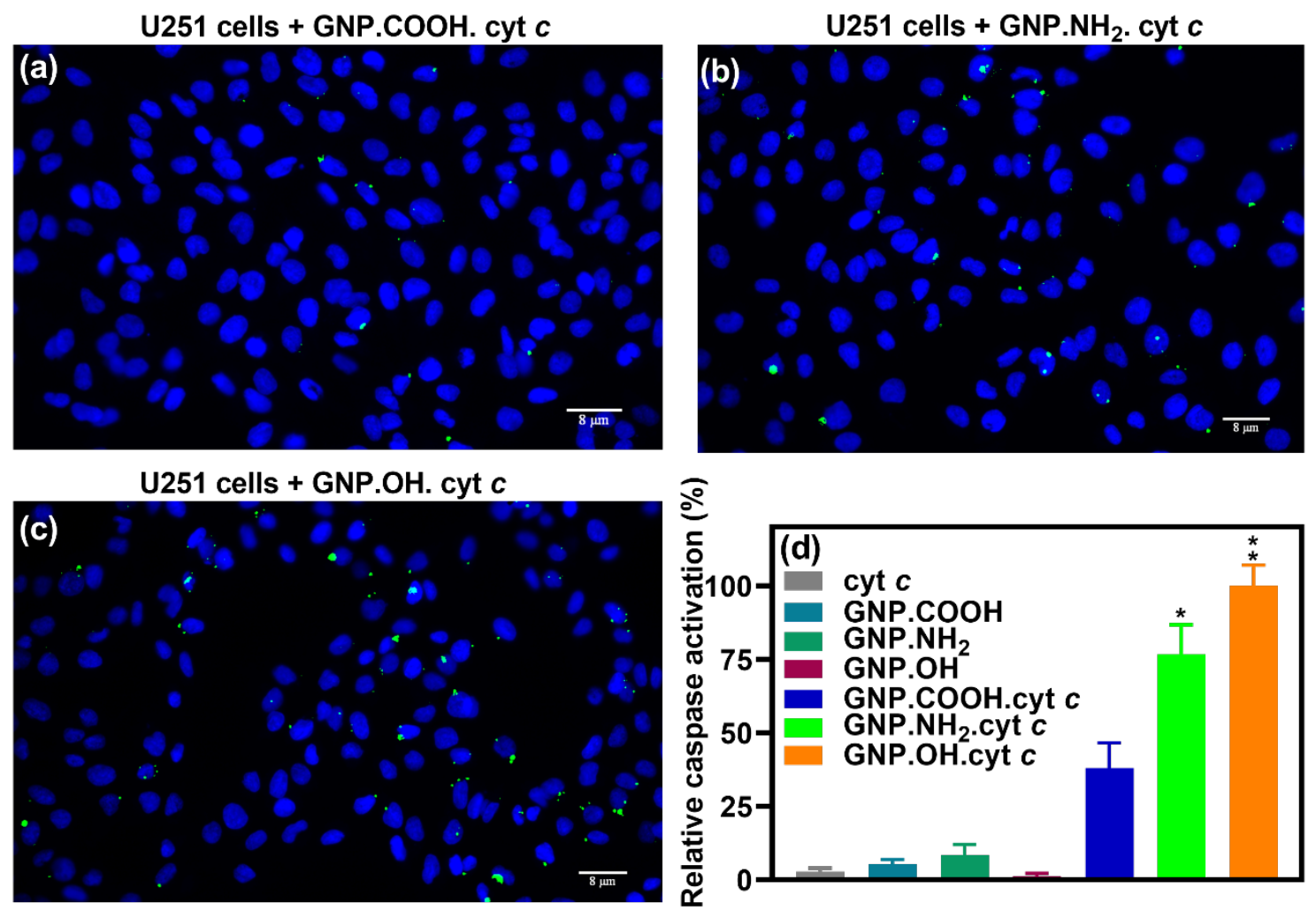

Figure 5. Fluorescent Caspase activity assay. (a-c) Confocal microscopy images of U251 cells incubated with different GNP. cyt $c$ conjugates for $4 \mathrm{~h}$, cells with green fluorescence are Caspase-3/7 positive cells. (d) Corrected total cell fluorescence as a function of relative Caspase activation induced by cyt $\mathrm{c}$ bound GNPs in U251 cells. All the values were normalized with fluorescent intensity obtained with GNP.OH.cyt $c$ samples. Error bars represent the SEM of fluorescent intensity of at least 25 different cells. $* \mathrm{P}<0.05$; $* * \mathrm{P}<0.01$ obtained using 2-way ANOVA with a Bonferroni post-test

Finally, to confirm whether the structural perturbation observed in the CD spectra of GNP.COOH.cyt $c$ sample is affecting its apoptotic activity, we tested the peroxidase activity of GNP.cyt $c$ conjugates. Since, it has been previously reported that the perturbation in the tertiary structure of cyt $c$ causes increased access to the heme ring that leads to an enhancement in peroxidase activity, ${ }^{[27,31]}$ a higher peroxidase activity of GNP.COOH.cyt $c$ would be expected compared to GNP.NH .cyt $c$ and GNP.OH.cyt $c$. Guaiacol, an oxidation indicator was used to monitor the peroxidase activity of cyt $c$ bound GNPs in the presence of $\mathrm{H}_{2} \mathrm{O}_{2}$. After incubating the different GNP samples at various concentrations with the substrate, we observed that 
GNP.COOH.cyt $c$ has the lowest peroxidase activity compared to GNP.NH2.cyt $c$ and GNP.OH.cyt $c$ samples (Figure 6). This data indicates that after structural perturbation in GNP.COOH.cyt $c$ samples, the heme ring is not easily accessible to the substrate for oxidation; this can only be the case when the heme is protected deep inside the protein structure. While in GNP.NH $\mathrm{NH}_{2}$.cyt $c$ and GNP.OH.cyt samples, the heme ring is more accessible and exposed to the external environment (as suggested by ToF-SIMS data), which contribute to the higher peroxidase activity. Moreover, we show GNPs modified with the ligand only had no significant peroxidase active. These results further highlight that both protein structure and orientation play a vital role in determining the activity of cyt $c$.

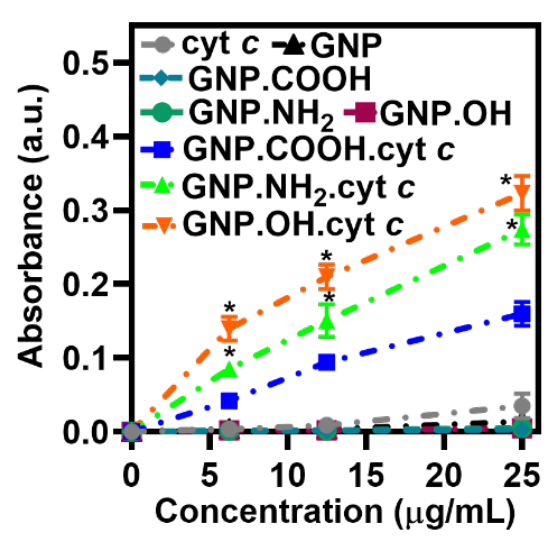

Figure 6. Orientation dependent Peroxidase activity of cyt $c$ bound GNPs using three different ligands as a function of their concentration. Experiment was performed in quadruplicates and results are expressed as mean \pm S.D. ${ }^{*} \mathrm{P}<0.05$ vs GNP.COOH.cyt $c$, obtained using 2-way ANOVA with a Tukey post-test.

\section{Conclusions}

In summary, we have demonstrated that the surface charge of the ligand on GNPs alters the conformation and orientation of cyt $c$. Anionic ligands cause perturbation in the tertiary structure of cyt $c$, while the structure was preserved on the cationic and neutral ligands. The adsorption of cyt $c$ on anionic and cationic or neutral ligand is facilitated by the interaction with Lys and Glu residues, respectively. We have further identified that the apoptotic and peroxidase activity of cyt $c$, when bound to GNPs, is dependent on the position of the heme ring with 
respect to its structure. A specific orientation with exposed heme ring favored apoptotic activity, because of easier access of heme edge for interaction with the apoptosis initiating protein (APAF-1). In contrast, suppressed apoptotic activity is observed for the opposite orientation with the heme ring protected. This study shows that by changing the surface charge of the ligand on the NP surface, the activity of cyt $c$ can be modulated to achieve the desired response. We anticipate that these novel findings will facilitate the design and application of new sensors and protein-based nanomedicine for a broad range of diseases.

\section{Experimental Section}

Materials: All the reagents were of analytical grade and were used as supplied without further purification unless specified. Citrate-capped spherical gold nanoparticles of size $125 \mathrm{~nm}$ were purchased from NanopartzTM, USA. Phosphate buffer saline (PBS, $10 \mathrm{mM}$ ), Horse heart cytochrome $c$, Thiol-PEG-Amine (MW = 2,000 Da), Trypsin, Bradford reagent and Guaiacol were purchased from Sigma-Aldrich, UK. Thiol-PEG-Acid and Thiol-PEG-Hydroxyl (MW = 2,000 Da) were purchased from Nanocs, USA. Caspase-3 assay kit (Colorimetric) was purchased from Abcam, Cambridge, UK. CellEventTM Caspase-3/7 Green detection reagent was bought from Invitrogen, ThermoFisher Scientific, UK.

Surface functionalization of gold nanoparticles: Cytochrome $c$ (cyt $c$ ) was electrostatically adsorbed on gold nanoparticles (GNPs) using a two-step procedure. In the first step, GNPs were functionalized with a hetero-bifunctional PEG to obtain water soluble GNPs. Briefly, $10 \mathrm{~mL}$ of SH-PEG-COOH or SH-PEG-NH2 or SH-PEG-OH $(500 \mu \mathrm{M})$ solution in water was added to 10 $\mathrm{mL}$ citrate-capped GNPs $(50 \mu \mathrm{g} / \mathrm{mL})$. The solution was stirred overnight at room temperature. Later, the GNPs were centrifuged at $2500 \mathrm{rpm}$ for $20 \mathrm{~min}$ and washed 4 times to obtain PEGylated GNPs named as GNP.COOH, GNP.NH 2 and GNP.OH. In the second step, $10 \mathrm{~mL}$ of cyt $\mathrm{c}$ was added to $10 \mathrm{~mL}$ PEGylated GNPs (GNP.COOH, GNP.NH $\mathrm{N}_{2}$ and GNP.OH) and the solution was stirred at room temperature for $24 \mathrm{~h}$. Various concentrations of cyt c $(100,150$, and $200 \mu \mathrm{M}$ ) were used to optimize its binding on PEGylated GNPs. Finally, the GNPs were 
centrifuged at $2500 \mathrm{rpm}$ for $20 \mathrm{~min}$ and washed 4 times with water to obtain GNP.COOH.cyt $c$, GNP.NH $2 . c y t ~ c$, and GNP.OH.cyt $c$.

\section{Supporting Information}

Additional information as noted in the text including characterization, detailed methodology of in vitro cell culture experiments, quantification of number of cyt $\mathrm{c}$ molecules bound to each GNPs using UV-Vis spectroscopy (Table S1) and XPS analysis (Table S2). TOF-SIMS intensity spectra of iron-porphyrin fragments (Figure S1). Cyclic volatmograms of scan rate and redox kinetics of different GNP.cyt $c$ nanoconjuages (Figure S2). Confocal microscopy images of ligand functionalized GNPs and other controls for fluorescent Caspase 3-7 activity assay (Figure S3). WST-8 metabolic activity assay (Figure S4).

\section{Acknowledgements}

This work is supported by the Engineering and Physical Sciences Research Council (EPSRC) Grant number EP/R004072/1, EU ERDF (FEDER) funds and Spanish government grant TEC2017-85059-C3-2-R. L.P.G. thanks the University of Nottingham for a Anne McLaren Research Fellowship. D.B.A. thanks the EPSRC for funding [EP/M005178/1]. Dr. Scott Young and Dr. Saul Vazquez-Reina are thanked for their assistance with ICP-MS analysis. Dr. Mario Samperi is thanked for assistance with circular dichroism analysis. We thank the Nanoscale and Microscale Research Centre (nmRC) for providing access to instrumentation. Dr. Nigel Neate and Dr. Craig Stoppiello are thanked for assistance on TEM and XPS analysis, respectively.

\section{Authors contribution}

A.J., F.J.R., D.B.A., L.P.G., R.R., and R.J.H. conceived, designed and initiated the work. A.J. and J.C.P. synthesized and characterized the surface-functionalized gold nanoparticles. A.J. did the Circular Dichroism analysis. G.F.T. performed the ToF-SIMS measurements and analyzed the data. J.M.H. performed and analyzed the electrochemical work. A.J. performed all the cell studies. A.J., F.J.R., and J.M.H. wrote the manuscript. All authors discussed experiment design and findings. All authors read, commented, and approved the final manuscript. 


\section{Conflict of interest}

The authors declare no conflict of interest.

\section{Keywords}

gold nanoparticles, cytochrome $c$, orientation, apoptosis, peroxidase activity

Received: ((will be filled in by the editorial staff))

Revised: ((will be filled in by the editorial staff))

Published online: ((will be filled in by the editorial staff))

\section{References}

[1] a) P. M. Mendes, Chem. Soc. Rev. 2013, 42, 9207; b) F. Rawson, C. Yeung, S. Jackson, P. Mendes, Nano Lett. 2012, 13, 1; c) P. Zhang, L. Chen, T. Xu, H. Liu, X. Liu, J. Meng, G. Yang, L. Jiang, S. Wang, Adv. Mater. 2013, 25, 3566.

[2] A. J. Sivaram, A. Wardiana, C. B. Howard, S. M. Mahler, K. J. Thurecht, Adv. Healthcare Mater. 2018, 7, 1700607.

[3] a) S. Rana, Y.-C. Yeh, V. M. Rotello, Curr. Opin. Chem. Biol. 2010, 14, 828; b) R. Solaro, F. Chiellini, A. Battisti, Materials 2010, 3, 1928; c) C. D. Spicer, C. Jumeaux, B. Gupta, M. M. Stevens, Chem. Soc. Rev. 2018, 47, 3574; d) A. Kapur, F. Aldeek, X. Ji, M. Safi, W. Wang, A. Del Cid, O. Steinbock, H. Mattoussi, Bioconj. Chem. 2017, 28, 678; e) M. De, S. Rana, H. Akpinar, O. R. Miranda, R. R. Arvizo, U. H. Bunz, V. M. Rotello, Nature Chem. 2009, 1, 461; f) J. R. Ashton, E. B. Gottlin, E. F. Patz, Jr., J. L. West, C. T. Badea, PLoS One 2018, 13, e0206950; g) S. Mao, G. Lu, K. Yu, Z. Bo, J. Chen, Adv. Mater. 2010, 22, 3521.

[4] a) G. A. Pietersz, X. Wang, M. L. Yap, B. Lim, K. Peter, Nanomedicine 2017, 12, 1873;

b) K. Ulbrich, K. Hola, V. Subr, A. Bakandritsos, J. Tucek, R. Zboril, Chem. Rev. 2016, 116, 5338; c) G. Y. Tonga, K. Saha, V. M. Rotello, Adv. Mater. 2014, 26, 359.

[5] a) K. Kalimuthu, B.-C. Lubin, A. Bazylevich, G. Gellerman, O. Shpilberg, G. Luboshits, M. A. Firer, J. Nanobiotechnol.2018, 16, 34; b) L. Cheng, L. Yang, F. Meng, Z. Zhong, Adv. Healthcare Mater. 2018, 7, 1800685.

[6] a) J. Cai, J. Yang, D. Jones, BBA-Bioenergetics 1998, 1366, 139; b) M. Hüttemann, P. Pecina, M. Rainbolt, T. H. Sanderson, V. E. Kagan, L. Samavati, J. W. Doan, I. Lee, Mitochondrion 2011, 11, 369.

[7] W. R. Fisher, H. Taniuchi, C. B. Anfinsen, J. Biol. Chem. 1973, 248, 3188.

[8] G. C. Brown, V. Borutaite, BBA-Bioenergetics 2008, 1777, 877. 
[9] M. Saxena, Y. Delgado, R. K. Sharma, S. Sharma, S. L. P. D. L. Guzmán, A. D. Tinoco, K. Griebenow, PLoS One 2018, 13, e0195542.

[10] A. Fu, R. Tang, J. Hardie, M. E. Farkas, V. M. Rotello, Bioconj. Chem. 2014, 25, 1602.

[11] a) I. I. Slowing, B. G. Trewyn, V. S.-Y. Lin, J. Am. Chem. Soc. 2007, 129, 8845; b) S. K. Kim, M. B. Foote, L. Huang, Biomaterials 2012, 33, 3959; c) W. Al-Shakarchi, A. Alsuraifi, M. Abed, M. Abdullah, A. Richardson, A. Curtis, C. Hoskins, Pharmaceutics 2018, 10, 48 .

[12] a) A. A. Vertegel, R. W. Siegel, J. S. Dordick, Langmuir 2004, 20, 6800; b) P. Roach, D. Farrar, C. C. Perry, J. Am. Chem. Soc. 2006, 128, 3939; c) M. E. Aubin-Tam, K. Hamad-Schifferli, Langmuir 2005, 21, 12080; d) L. Shang, L. Yang, J. Seiter, M. Heinle, G. Brenner-Weiss, D. Gerthsen, G. U. Nienhaus, Adv. Mater. Interfaces 2014, 1, 1300079.

[13] a) H. Bayraktar, C.-C. You, V. M. Rotello, M. J. Knapp, J. Am. Chem. Soc. 2007, 129, 2732; b) M. E. Aubin-Tam, W. Hwang, K. Hamad-Schifferli, Proc. Natl. Acad. Sci. U. S. A. 2009, 106, 4095.

[14] a) W. Shang, J. H. Nuffer, V. A. Muñiz-Papandrea, W. Colón, R. W. Siegel, J. S. Dordick, Small 2009, 5, 470; b) S. Maiti, K. Das, S. Dutta, P. K. Das, Chem. Eur. J. 2012, 18, 15021.

[15] a) E. Matysiak-Brynda, B. Wagner, M. Bystrzejewski, I. P. Grudzinski, A. M. Nowicka, Biosens. Bioelectron. 2018, 109, 83; b) L. M. Herda, D. R. Hristov, M. C. Lo Giudice, E. Polo, K. A. Dawson, J. Am. Chem. Soc. 2016, 139, 111; c) F. Liu, L. Wang, H. Wang, L. Yuan, J. Li, J. L. Brash, H. Chen, ACS Appl. Mater. \& Interfaces 2015, 7, 3717; d) D. Wasserberg, J. Cabanas-Danés, J. Prangsma, S. O’Mahony, P.-A. Cazade, E. Tromp, C. Blum, D. Thompson, J. Huskens, V. Subramaniam, ACS Nano 2017, 11, 9068; e) S. Mazzucchelli, M. Colombo, P. Verderio, E. Rozek, F. Andreata, E. Galbiati, P. Tortora, F. Corsi, D. Prosperi, Angew. Chem. Int. Ed. 2013, 52, 3121; f) K. W. Yong, D. Yuen, M. Z. Chen, C. J. Porter, A. P. Johnston, Nano Lett. 2019, 19, 1827; g) P. Zhang, L. Zhang, Z. Qin, S. Hua, Z. Guo, C. Chu, H. Lin, Y. Zhang, W. Li, X. Zhang, Adv. Mater. 2018, 30, 1705350.

[16] a) J. Xu, E. F. Bowden, J. Am. Chem. Soc. 2006, 128, 6813; b) S. Lin, X. Jiang, L. Wang, G. Li, L. Guo, J. Phys. Chem. C 2011, 116, 637; c) K. Ataka, J. Heberle, J. Am. Chem. Soc. 2004, 126, 9445; d) C. E. Caesar, E. K. Esbjörner, P. Lincoln, B. Nordén, Biophys. J. 2009, 96, 3399; e) J. M. Pachence, S. Amador, G. Maniara, J. Vanderkooi, P. Dutton, J. Blasie, Biophys. J. 1990, 58, 379; f) A. Tronin, A. M. Edwards, W. W. Wright, J. M. 
Vanderkooi, J. K. Blasie, Biophys. J. 2002, 82, 996; g) J. Zhou, J. Zheng, S. Jiang, J. Phys. Chem. B 2004, 108, 17418; h) G. Di Palma, A. M. Kotowska, L. R. Hart, D. J. Scurr, F. J. Rawson, S. Tommasone, P. M. Mendes, ACS Appl. Mater. \& Interfaces 2019, 11, 8937.

[17] E. J. Tollefson, C. R. Allen, G. Chong, X. Zhang, N. D. Rozanov, A. Bautista, J. J. Cerda, J. A. Pedersen, C. J. Murphy, E. E. Carlson, ACS Nano 2019, 13, 6856.

[18] a) Y.-C. Yeh, B. Creran, V. M. Rotello, Nanoscale 2012, 4, 1871; b) N. R. Jana, J. Y. Ying, Adv. Mater. 2008, 20, 430; c) K. C. Kwon, E. Jo, Y. W. Kwon, B. Lee, J. H. Ryu, E. J. Lee, K. Kim, J. Lee, Adv. Mater. 2017, 29, 1701146; d) X. Cheng, R. Sun, L. Yin, Z. Chai, H. Shi, M. Gao, Adv. Mater. 2017, 29, 1604894; e) W. Chen, S. Zhang, Y. Yu, H. Zhang, Q. He, Adv. Mater. 2016, 28, 8567.

[19] a) P. L. Edmiston, J. E. Lee, S.-S. Cheng, S. S. Saavedra, J. Am. Chem. Soc. 1997, 119, 560; b) L. Banci, I. Bertini, H. B. Gray, C. Luchinat, T. Reddig, A. Rosato, P. Turano, Biochemistry 1997, 36, 9867; c) G. W. Bushnell, G. V. Louie, G. D. Brayer, J. Mol. Biol. 1990, 214, 585.

[20] S. Ferretti, S.-K. Lee, B. D. MacCraith, A. G. Oliva, D. J. Richardson, D. A. Russell, K. E. Sapsford, M. Vidal, Analyst 2000, 125, 1993.

[21] C. Kawai, F. M. Prado, G. L. Nunes, P. Di Mascio, A. M. Carmona-Ribeiro, I. L. Nantes, J. Biol. Chem. 2005, 280, 34709 .

[22] N. J. Greenfield, Nature Protoc. 2006, 1, 2876.

[23] S. Vinogradov, R. Zand, Arch. Biochem. Biophys. 1968, 125, 902.

[24] J. E. Baio, T. Weidner, D. Ramey, L. Pruzinsky, D. G. Castner, Biointerphases 2013, 8, 18.

[25] A. K. Yagati, T. Lee, J. Min, J.-W. Choi, Colloids Surf. B. Biointerfaces 2012, 92, 161.

[26] X. Chen, R. Ferrigno, J. Yang, G. M. Whitesides, Langmuir 2002, 18, 7009.

[27] L. Tarpani, F. Bellezza, P. Sassi, M. Gambucci, A. Cipiciani, L. Latterini, J. Phys. Chem. B 2019, 123, 2567.

[28] D. P. Reinhardt, R. N. Ono, L. Y. Sakai, J. Biol. Chem. 1997, 272, 1231.

[29] S. Santra, C. Kaittanis, J. M. Perez, Mol. Pharm. 2010, 7, 1209.

[30] a) D. N. Shalaeva, D. V. Dibrova, M. Y. Galperin, A. Y. Mulkidjanian, Biol. Direct 2015, 10, 29; b) L. Dorstyn, C. W. Akey, S. Kumar, Cell Death \& Differ. 2018, 25, 1194; c) S. Yuan, M. Topf, T. F. Reubold, S. Eschenburg, C. W. Akey, Biochemistry 2013, 52, 2319. 
[31] P. Weinkam, J. r. Zimmermann, F. E. Romesberg, P. G. Wolynes, Acc. Chem. Res. 2010, 43,652 . 


\section{Supporting Information}

Modulating the Biological Function of Protein by Tailoring the Adsorption Orientation on Nanoparticles

Akhil Jain, Gustavo F. Trindade, Jacqueline M. Hicks, Jordan C. Potts, Ruman Rahman, Richard J. M. Hague, David B. Amabilino, Llü̈sa Pérez-García, and Frankie J. Rawson*

Dr. Akhil Jain, Dr. Jacqueline M. Hicks, Dr. Frankie J. Rawson*

Division of Regenerative Medicine and Cellular Therapies

School of Pharmacy

University of Nottingham, Nottingham NG7 2RD, UK

*E-mail: Frankie.Rawson@nottingham.ac.uk

Dr. Gustavo F. Trindade, Jordan C. Potts and Dr. Lluïsa Pérez-García

Division of Advanced Materials and Healthcare Technologies

School of Pharmacy

University of Nottingham, Nottingham NG7 2RD, UK

Dr. Ruman Rahman

Children's Brain Tumour Research Centre

School of Medicine

University of Nottingham, Nottingham NG7 2UH, UK

Prof. Richard J. M. Hague

Centre for Additive Manufacturing

Faculty of Engineering

University of Nottingham, Nottingham NG8 1BB, UK

Prof. David B. Amabilino

GSK Carbon Neutral Laboratories for Sustainable Chemistry

School of Chemistry

University of Nottingham, Nottingham NG7 2TU, UK 


\section{Characterization}

Transmission Electron Microscopy (TEM): Size and morphology of the GNPs was analyzed using a transmission electron microscope (JEOL 2000 FX TEM) operating at $200 \mathrm{kV}$ accelerating voltage. TEM samples were prepared by dropping $15 \mu \mathrm{L}$ of GNPs on a carboncoated copper grid (400 Mesh, Agar Scientific), the samples were allowed to sit on the grid for at least $3 \mathrm{~h}$ before imaging. Histogram of particle size distribution was obtained by analyzing 100 different nanoparticles of each sample.

Dynamic Light Scattering and Zeta Potential: The hydrodynamic diameter and Zeta potential of the GNPs were recorded using a Malvern Zetasizer Nano-ZS ((Malvern Instruments, UK). $\boldsymbol{U} \boldsymbol{V}$-Vis Absorption Spectroscopy: UV-Vis absorption spectra were recorded on a CARY 50 Bio Spectrophotometer (Varian).

X-ray Photoelectron Spectroscopy: Samples were analyzed using the Kratos AXIS ULTRA with a monochromatic $\mathrm{Al} \mathrm{k} \alpha \mathrm{X}$-ray source $(1486.6 \mathrm{eV})$ operated at $10 \mathrm{~mA}$ emission current and $12 \mathrm{kV}$ anode potential $(120 \mathrm{~W})$ Spectra were acquired with the Kratos VISION II software. A charge neutralizer filament was used to prevent surface charging. Hybrid -slot mode was used measuring a sample area of approximately $300 \times 700 \mu \mathrm{m}$. Three repeats of each sample with three different areas were performed. A wide scan at low resolution (Binding energy range 1400 $\mathrm{eV}$ to $-5 \mathrm{eV}$, with pass energy $80 \mathrm{eV}$, step $0.5 \mathrm{eV}$, sweep time 20 minutes) was used to estimate the total atomic $\%$ of the detected elements. High-resolution spectra at pass energy $20 \mathrm{eV}$, a step of $0.1 \mathrm{eV}$, and sweep times of 10 minutes each were also acquired for photoelectron peaks from the detected elements and these were used to model the chemical composition. The spectra were charge corrected to the $\mathrm{C}$ 1s peak (adventitious carbon or a known polymer $\mathrm{CH}_{2}$ or $\mathrm{CH}_{3}$ peak) set to $285 \mathrm{eV}$. The amount of cyt $c$ on the surface of GNPs was determined by analyzing the atomic percentage of nitrogen ( $\mathrm{N}$ 1s signal). For GNP.NH $2 . c y t c$ samples, where Nitrogen (N) can also be detected to its presence in the GNP. $\mathrm{NH}_{2}$, normalization with respect to both $\mathrm{N}$ 
and $\mathrm{Au}$ (atomic percentage) before and after cyt $c$ binding was performed and Equation 1 was used to calculate the $\mathrm{N}_{\text {norm }}{ }^{[1]}$.

$$
\mathrm{N}_{\text {norm }}=\mathrm{N}_{\mathrm{p}}-\mathrm{N}_{\mathrm{b}}\left(\mathrm{Au}_{\mathrm{p}}-\mathrm{Au}_{\mathrm{b}}\right)
$$

In Equation $1, \mathrm{~N}_{\mathrm{b}}$ and $\mathrm{Au}_{\mathrm{b}}$ are the calculated atomic percentage of $\mathrm{N}$ and $\mathrm{Au}$, respectively, from the GNP.NH 2 samples i.e. before cyt $c$ binding. $\mathrm{Np}$ and $\mathrm{Au}_{\mathrm{p}}$ are the measured atomic percentage of $\mathrm{N}$ and $\mathrm{Au}$, respectively, from the GNP. $\mathrm{NH}_{2}$.cyt $c$ samples.

Circular Dichroism: Far and near UV CD spectra were recorded at $20^{\circ} \mathrm{C}$ on a Chirascan CD spectrophotometer (Applied Photophysics) equipped with a temperature control unit TC125 (Quantum Northwest). All the samples and cyt c were dispersed in $10 \mathrm{mM}$ PBS at pH 7.4. Three spectra were taken for each sample and averaged. A quartz cuvette with an optical pathlength of $1 \mathrm{~cm}$ was used for all the UV-Vis and CD measurements.

Time of Flight-Secondary Ion Mass Spectrometry (ToF-SIMS): For ToF-SIMS analysis, samples were drop casted onto IPA-wiped microscopy glass slides and dried in vacuum. ToFSIMS analysis of positively and negatively charged secondary ions was carried out using a TOF.SIMS IV system from ION-TOF GmbH (Münster, Germany). For each sample, spectra were acquired using a $25 \mathrm{keV} \mathrm{Bi}^{3+}$ primary ion beam operated in the high current bunched mode delivering $0.3 \mathrm{pA}$ and raster scanned 30 times over a $100 \times 100 \mu \mathrm{m}^{2}$ area, which kept the total dose under the static limit of 1012 ions $/ \mathrm{cm}^{2}$. A low-energy $(20 \mathrm{eV})$ electron flood gun was employed to neutralize charge build-up. The ToF analyzer was set with $200 \mu$ s cycle time, resulting in a mass range between 0 and 3492 mass units. To account for variability, 6 spectra were acquired at different regions of each sample and near the center of the formed films. Control spectra of pure gold nanoparticles and clean glass substrate were also measured. Electrochemical Studies: The analyses were conducted using a Metrohm Autolab M204 potentiostat and a three-electrode system within a Faraday cage (Princeton Applied Research). This consisted of a platinum wire counter electrode, an $\mathrm{Ag} / \mathrm{AgCl}$ reference electrode (both from 
ALS Co. Ltd.) and an indium tin oxide (ITO, Delta Technologies Ltd.) working electrode. To construct the working electrode ITO coated glass was cut to approximately $10 \mathrm{~mm} \times 20 \mathrm{~mm}$; this was washed briefly with acetone and water, dried with argon gas and assembled into an electrochemical cell with an exposed working area of $38.48 \mathrm{~mm}^{2}$. A new ITO working electrode was used for every sample tested. GNPs were dispersed in PBS to a final working concentration of $25 \mu \mathrm{g} / \mathrm{mL}$ (determined by UV-Vis). Cyclic voltammetry (CV) was conducted between 0.4 $\mathrm{V}$ and $-0.2 \mathrm{~V}$ at varying scan rates between $50 \mathrm{mV} . \mathrm{s}^{-1}$ and $2 \mathrm{~V} . \mathrm{s}^{-1}$. Repetitive consecutive CVs were conducted at a fixed scan rate of $100 \mathrm{mV} \cdot \mathrm{s}^{-1}$. Control CVs were conducted with unmodified gold nanoparticles using PBS as the supporting electrolyte.

Proteolytic Degradation Assay: The assay was performed using the protocol reported earlier. ${ }^{[2]}$ In a typical experiment, $1 \mathrm{~mL}$ of $25 \mu \mathrm{g} / \mathrm{mL}$ cyt c bound GNPs were incubated with 4 mg of trypsin for $1,4,8$ and $24 \mathrm{~h}$ at $37{ }^{\circ} \mathrm{C}$. The degradation of cyt $c$ was determined by monitoring the absorbance at $409 \mathrm{~nm}$.

Cell Culture: Malignant Glioblastoma cell line U251 were purchased from ATCC, USA and cultured in DMEM (Gibco) supplemented with 10\% fetal bovine serum (FBS) and 1\% penicillin/streptomycin. Cells were maintained at $37{ }^{\circ} \mathrm{C}$ in an incubator with humidified atmosphere, containing $5 \% \mathrm{CO}_{2}$.

Cellular uptake analysis: For cellular uptake analysis, $0.5 \times 10^{5}$ U251 cells were seeded on 6well plate and incubated at $37^{\circ} \mathrm{C}$ for $24 \mathrm{~h}$. After $24 \mathrm{~h}$, the culture medium was replaced with fresh medium containing $25 \mu \mathrm{g} / \mathrm{mL}$ GNP functionalized with/ without cyt $c$ and incubated for 1 and $4 \mathrm{~h}$. After each incubation period the media was removed, and cells were washed three times with PBS to remove unbound/loosely bound GNPs. Cells were trypsinized and $50 \mu \mathrm{L}$ of cell suspension was used for trypan blue cell viability assay. The remaining cell suspension was centrifuged at $200 \times \mathrm{g}$ for $5 \mathrm{~min}$. The obtained pellet was digested overnight with $5 \%$ aquaregia. Later the solutions were diluted with milliQ water to reach the final concentration of acid to $2 \%$ 
and taken for ICP-MS analysis (iCAPQ Thermo Fischer). The number of GNPs inside each cell was determined using the method reported earlier. ${ }^{[3]}$

Colorimetric Caspase-3 assay: For caspase-3 detection, two different approaches were studied. In the first approach the cells were first lysed to extract the cytosol, followed by GNP treatment to induce apoptosis and finally caspase- 3 detection. While in the second approach, treatment with GNPs was given to the cells, followed by cytosol extraction and caspase-3 detection. In a typical experiment, $0.5 \times 10^{5} \mathrm{U} 251$ cells were seeded on 6 -well plate and incubated at $37^{\circ} \mathrm{C}$ for $24 \mathrm{~h}$. Next, the culture medium was replaced with fresh medium containing $25 \mu \mathrm{g} / \mathrm{mL}$ GNPs functionalized with/ without cyt $c$ and incubated for 1 and $4 \mathrm{~h}$. Afterwards, cells were trypsinized and $1 \times 10^{6}$ cells were counted and resuspended in the $50 \mu \mathrm{L}$ of chilled lysis buffer (supplied with the caspase-3 assay kit) and incubated in ice for 10 minutes. Later, the cells were centrifuged at $10,000 \times \mathrm{g}$ for 1 minute and the supernatant (cytosol) was transferred to a fresh tube. The protein content in the cytosolic extract was determined using the Bradford assay. For the second approach, the fresh cytosol (extracted using the protocol discussed above) was incubated with $25 \mu \mathrm{g} / \mathrm{mL}$ GNPs functionalized with/without cyt $c$ and $2 \mu \mathrm{M}$ free cyt $c$ for 1 and 4 h. Finally, Caspase-3 assay was performed following the manufacturer's protocol in a 96well plate. A total of $50 \mu \mathrm{L}$ of $2 \mathrm{X}$ reaction buffer (containing $10 \mathrm{mM}$ DTT) was added to 50 $\mu \mathrm{L}$ of each sample (in triplicate), followed by addition of $5 \mu \mathrm{L}$ of the $4 \mathrm{mM}$ DEVD-p-NA substrate. The reaction was incubated at $37^{\circ} \mathrm{C}$ for $90 \mathrm{~min}$ and the absorbance of the sample was read at $400 \mathrm{~nm}$ on a Tecan microplate reader. A sample without any treatment with GNPs or cyt $c$ was taken as control. Background reading from $50 \mu \mathrm{L}$ cytosol incubated with $50 \mu \mathrm{L}$ reaction buffer was subtracted from both test and control samples. The experiments were repeated three times using triplicates.

Fluorescent Caspase-3/7 assay: $0.5 \times 10^{5}$ U251 cells were seeded on a $35 \mathrm{~mm}$ glass-bottom dish (ThermoFisher SCIENTIFIC) and incubated at $37^{\circ} \mathrm{C}$ for $24 \mathrm{~h}$. After $24 \mathrm{~h}$, the culture medium was replaced with fresh medium containing $25 \mu \mathrm{g} / \mathrm{mL}$ GNPs functionalized with/ 
without cyt $c$ and incubated for $4 \mathrm{~h}$. After $4 \mathrm{~h}$, media containing GNPs was removed and cells were washed three times with PBS. Next, the cells were incubated with $8 \mu \mathrm{M}$ CellEventTM Caspase 3-7 green detection reagent in PBS containing 5\% FBS for $30 \mathrm{~min}$ at $37^{\circ} \mathrm{C}$. Afterwards, the cells were preserved with $3.7 \%$ formaldehyde for $15 \mathrm{~min}$ and subsequently washed with PBS. Later the cells were treated with DAPI for 5 min at RT under dark and washed again with PBS. Finally, the cells were immersed in PBS and imaged using Zeiss Elyra confocal microscope at 20x objective using the filter settings of Alexa Fluor 488 dye. The green fluorescent intensity values were normalized to the total number of cells per field and expressed as corrected total cell fluorescence (CTCF) obtained by Equation 2:

Corrected total cell fluorescence $=$ Integrated density $-($ area of selected cell $\times$ Mean fluorescence of background signal)

WST-8 metabolic activity assay: Biocompatibility of GNPs and cyt $c$ bound GNPs was studied using WST-8 assay. A total of $1 \times 10^{4} \mathrm{U} 251$ cells were incubated on 96 well plates $24 \mathrm{~h}$ prior experiment. During the next step, the culture media was replaced with medium containing GNPs $(12.5$ or $25 \mu \mathrm{g} / \mathrm{mL})$ and incubated for $4 \mathrm{~h}$. Next, media was replaced with $10 \% \mathrm{WST}-8$ in complete DMEM and incubated for an hour before reading the absorbance at $450 \mathrm{~nm}$ in a Tecan microplate reader. Culture media and 3\% Triton X-100 were taken as negative and positive control respectively. Values are presented relative to negative controls.

Peroxidase activity: To determine the peroxidase activity, the oxidation of Guaiacol (2methoxyhenol) by $\mathrm{H}_{2} \mathrm{O}_{2}$ in the presence/ absence of native cyt $c$ and GNPs functionalized with cyt $c$ was recorded. GNP-cyt $c$ conjugates $(1 \mathrm{~mL})$ in various concentrations $(6.25,12.5$, and $25 \mu \mathrm{g} / \mathrm{mL})$ was added to $2.5 \mu \mathrm{M}$ Guaiacol $(1 \mathrm{~mL})$ and finally $250 \mu \mathrm{M} \mathrm{H}_{2} \mathrm{O}_{2}$ was added and incubated for $5 \mathrm{~min}$ and absorbance was taken at $470 \mathrm{~nm}$. PBS (1 mL), $2.5 \mu \mathrm{M}$ Guaiacol $(1 \mathrm{~mL})$ and $250 \mu \mathrm{M} \mathrm{H}_{2} \mathrm{O}_{2}(1 \mathrm{~mL})$ was taken as control.

Statistical analysis: All the statistical analyses were performed using GraphPad Prism v8.2.1 software (GraphPad Software, Inc). All the data is expressed as mean \pm S.D., unless specified. 
For responses that were affected by two variables, a 2-way ANOVA with a Tukey post-test was used. Results are expressed as mean \pm SEM and a $\mathrm{P} \leq 0.05$ was considered significant. 
Table S1. Quantification of the cyt $c$ bound to each GNPs from the data obtained from UV-Vis measurements. Highlighted in yellow are the samples that were used in all the experiments reported in this work.

\begin{tabular}{|c|c|c|c|c|c|c|c|}
\hline Cyt $c$ & $\begin{array}{c}\text { Abs }^{\mathrm{a}} \\
\text { Soret band }\end{array}$ & $\begin{array}{c}A^{A b s^{s b}} \\
470 \mathrm{~nm}\end{array}$ & $\operatorname{Abs}^{f}$ & $\begin{array}{c}\varepsilon \\
\left(M^{-1} \mathrm{~cm}^{-1}\right)\end{array}$ & $\begin{array}{l}\text { cyt c } \\
\text { (M) }\end{array}$ & $\begin{array}{l}\text { No. of Molecules } \\
\text { (cyt c) }\end{array}$ & $\begin{array}{c}\text { Total surface area of } \\
\text { cyt } c \text { molecules } \\
\left(\mathrm{nm}^{2}\right)\end{array}$ \\
\hline GNP.COOH.cyt $c(100 \mu \mathrm{M})$ & 0.226 & 0.13 & 0.097 & \multirow{9}{*}{$1.01 \times 10^{5}$} & $0.96 \times 10^{-6}$ & $5.78 \times 10^{14}$ & $2.09 \times 10^{16}$ \\
\hline GNP.NH $2 . c y t c(100 \mu \mathrm{M})$ & 0.137 & 0.091 & 0.046 & & $0.4 \times 10^{-6}$ & $2.4 \times 10^{14}$ & $8.7 \times 10^{15}$ \\
\hline GNP.COOH.cyt $c(100 \mu \mathrm{M})$ & 0.129 & 0.094 & 0.035 & & $0.32 \times 10^{-6}$ & $1.92 \times 10^{14}$ & $6.97 \times 10^{15}$ \\
\hline GNP.COOH.cyt $c(150 \mu \mathrm{M})$ & 0.488 & 0.266 & 0.222 & & $2.1 \times 10^{-6}$ & $1.3 \times 10^{15}$ & $4.7 \times 10^{16}$ \\
\hline GNP.NH 2 .cyt $c(150 \mu \mathrm{M})$ & 0.207 & 0.11 & 0.094 & & $0.93 \times 10^{-6}$ & $5.6 \times 10^{14}$ & $2.03 \times 10^{16}$ \\
\hline GNP.OH.cyt $c(150 \mu \mathrm{M})$ & 0.157 & 0.088 & 0.069 & & $0.68 \times 10^{-6}$ & $4.09 \times 10^{14}$ & $1.48 \times 10^{16}$ \\
\hline GNP.COOH.cyt $c(200 \mu \mathrm{M})$ & 0.601 & 0.32 & 0.281 & & $2.8 \times 10^{-6}$ & $1.6 \times 10^{15}$ & $5.8 \times 10^{16}$ \\
\hline GNP.NH ${ }_{2}$.cyt $c(200 \mu \mathrm{M})$ & 0.286 & 0.14 & 0.146 & & $1.4 \times 10^{-6}$ & $8.4 \times 10^{14}$ & $3.05 \times 10^{16}$ \\
\hline GNP.OH.cyt $c(200 \mu \mathrm{M})$ & 0.553 & 0.31 & 0.253 & & $2.5 \times 10^{-6}$ & $1.5 \times 10^{15}$ & $5.4 \times 10^{16}$ \\
\hline GNP & Abs SPR & $\varepsilon\left(\mathbf{M}^{-1} \mathrm{~cm}^{-}\right)$ & Abs $_{450}$ & \multicolumn{2}{|c|}{ No. of GNP ${ }^{n}$} & $\begin{array}{l}\text { Total surface } \\
\text { area of GNPs sa } \\
\left(\mathrm{nm}^{2}\right)\end{array}$ & No. of cyt $c /$ GNP \\
\hline GNP.COOH.cyt $c(100 \mu \mathrm{M})$ & 0.35 & & 0.145 & \multicolumn{2}{|c|}{$3.6 \times 10^{8}$} & $2.03 \times 10^{13}$ & $\sim 1029$ \\
\hline GNP.NH $2 . c y t c(100 \mu \mathrm{M})$ & 0.325 & & 0.110 & \multicolumn{2}{|c|}{$2.7 \times 10^{8}$} & $1.5 \times 10^{13}$ & $\sim 580$ \\
\hline GNP.COOH.cyt $c(100 \mu \mathrm{M})$ & 0.257 & & 0.101 & \multicolumn{2}{|c|}{$2.47 \times 10^{8}$} & $1.4 \times 10^{13}$ & $\sim 497$ \\
\hline GNP.COOH.cyt $c(150 \mu \mathrm{M})$ & 0.661 & & 0.177 & \multicolumn{2}{|c|}{$4.39 \times 10^{8}$} & $2.48 \times 10^{13}$ & $\sim 1895$ \\
\hline GNP.NH ${ }_{2}$.cyt $c(150 \mu \mathrm{M})$ & 0.337 & $2.36 \times 10^{11}$ & 0.14 & \multicolumn{2}{|c|}{$3.5 \times 10^{8}$} & $1.97 \times 10^{13}$ & $\sim 1030$ \\
\hline GNP.OH.cyt $c(150 \mu \mathrm{M})$ & 0.235 & & 0.106 & \multicolumn{2}{|c|}{$2.6 \times 10^{8}$} & $1.46 \times 10^{13}$ & $\sim 1013$ \\
\hline GNP.COOH.cyt $c(200 \mu \mathrm{M})$ & 0.462 & & 0.215 & \multicolumn{2}{|c|}{$5.33 \times 10^{8}$} & $3.01 \times 10^{13}$ & $\sim 1926$ \\
\hline GNP.NH $2 . c y t c(200 \mu \mathrm{M})$ & 0.27 & & 0.178 & \multicolumn{2}{|c|}{$4.4 \times 10^{8}$} & $2.48 \times 10^{13}$ & $\sim 1229$ \\
\hline GNP.OH.cyt $c(200 \mu \mathrm{M})$ & 0.59 & & 0.374 & \multicolumn{2}{|c|}{$9.27 \times 10^{8}$} & $5.26 \times 10^{13}$ & $\sim 1026$ \\
\hline
\end{tabular}

a Abs: Absorbance; ${ }^{\mathbf{s b}}$ Abs of the sloping background; ${ }^{\mathbf{f}}$ Normalization of the Soret Band peak absorbance of the cyt $c$ was taken because of the influence on the spectra of the cyt $c$ bound GNP SPR peak (subtraction between the absorbance of the Soret Band peak of cyt $c$ at $409 \mathrm{~nm}$ and the absorbance of the cyt $c$ into cyt $c$ bound GNP sloping background at $470 \mathrm{~nm}$.

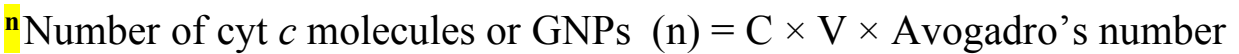

Where, $\mathrm{C}$ is concentration of cyt $c$ or GNPs; $\mathrm{V}=$ Volume in liters

${ }^{\text {sa }}$ Total surface area of cyt $c$ or GNPs $=4 \pi r^{2} \times n$

Where, $\mathrm{r}=$ radius of cyt $c$ or GNP; $\mathrm{n}=$ Number of cyt $c$ molecules or GNPs 
Table S2. Summary of elemental composition (in atomic percentage) for GNPs as determined by XPS analysis before and after cyt $c$ binding. Error bars represent standard deviations of atomic percentage obtained from three analysis spots on three different samples. Highlighted in yellow are the samples that were used in all the experiments reported in this work.

\begin{tabular}{cccccc}
\hline Sample name & Au (4f) & $\mathbf{C ~ ( 1 s )}$ & $\mathbf{O}(\mathbf{1 s})$ & $\mathbf{S ~ ( 2 p )}$ & $\mathbf{N}(\mathbf{1 s})$ \\
\hline Citrate-capped GNP & $67.1 \pm 0.8$ & $48.6 \pm 0.4$ & $4.3 \pm 0.6$ & - & - \\
\hline GNP.COOH & $52.2 \pm 4.8$ & $38.6 \pm 2.8$ & $5.9 \pm 0.2$ & $3.3 \pm 0.2$ & - \\
\hline GNP.NH ${ }_{2}$ & $45.1 \pm 3.7$ & $44.5 \pm 2.1$ & $6.9 \pm 0.3$ & $4.1 \pm 0.4$ & $1.8 \pm 0.2$ \\
\hline GNP.OH & $53.2 \pm 3.1$ & $36.8 \pm 1.7$ & $6.6 \pm 0.1$ & $3.4 \pm 0.2$ & - \\
\hline GNP.COOH.cyt c $(100 \mu \mathrm{M})$ & $49.3 \pm 1.5$ & $32.5 \pm 0.9$ & $6.7 \pm 0.3$ & $4.2 \pm 0.3$ & $7.3 \pm 0.5$ \\
\hline GNP.NH. cyt c $(150 \mu \mathrm{M})$ & $51.4 \pm 2.1$ & $31.3 \pm 2.4$ & $6.1 \pm 0.4$ & $4 \pm 0.2$ & $7.2 \pm 0.3\left(\mathrm{~N}_{\text {norm }}\right)$ \\
\hline GNP.OH.cyt c $(150 \mu \mathrm{M})$ & $48.7 \pm 2.6$ & $33.1 \pm 1.1$ & $7.2 \pm 0.6$ & $3.9 \pm 0.4$ & $7.1 \pm 0.3$ \\
\hline
\end{tabular}




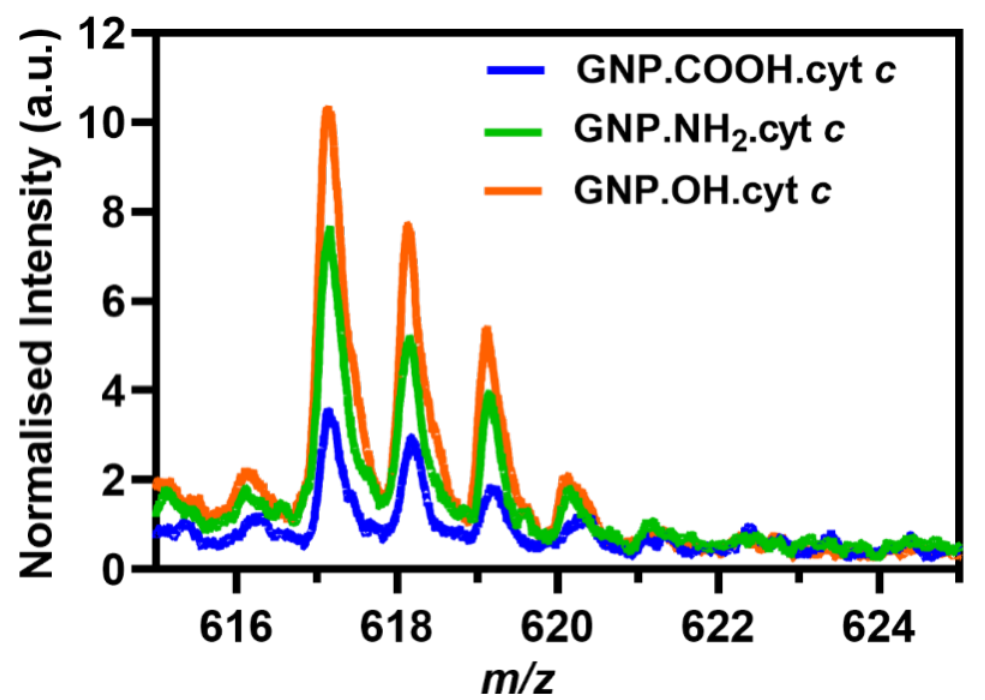

Figure S1. ToF-SIMS peak intensities spectra from heme ring fragment of cyt c bound GNP samples. 

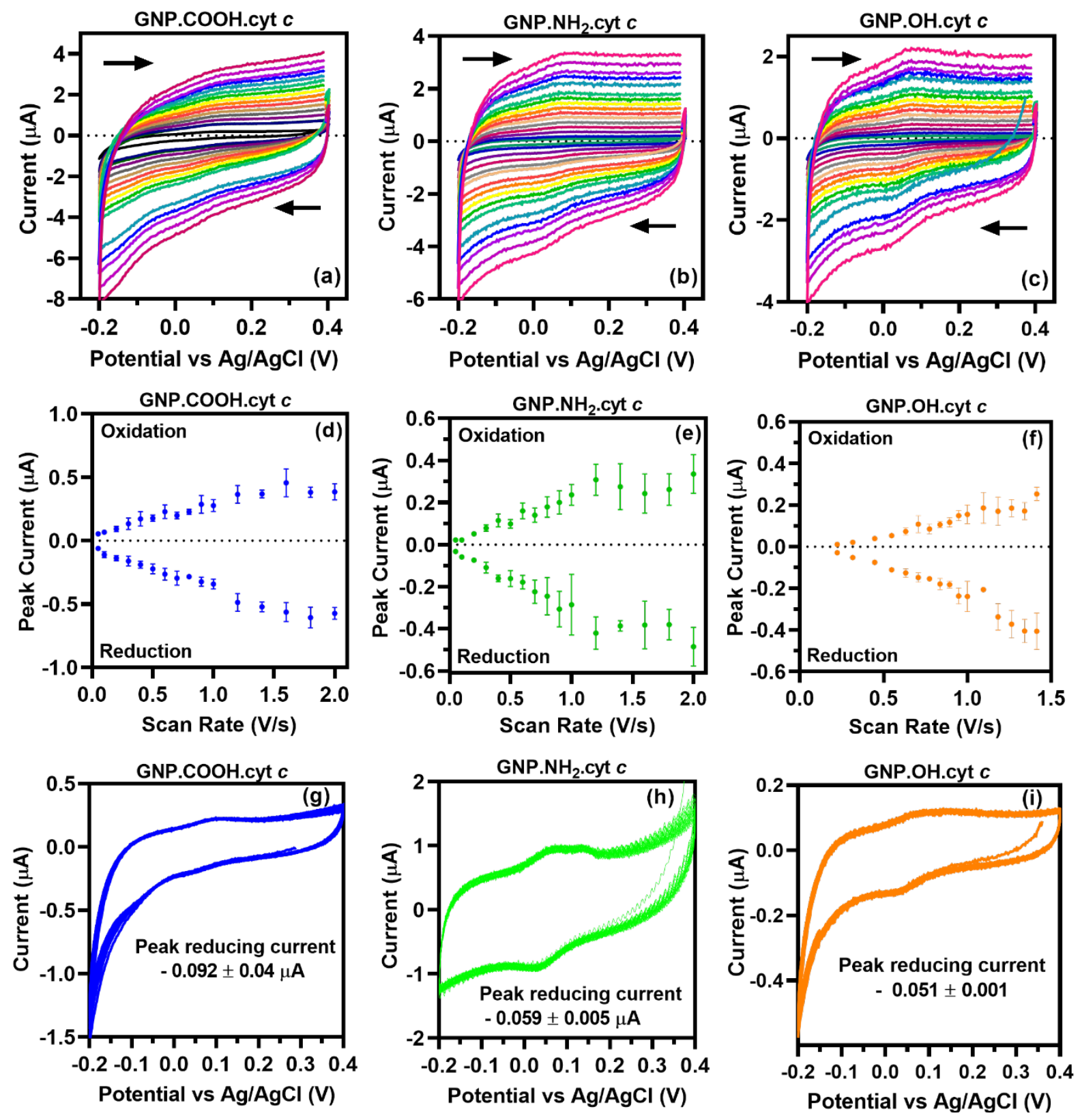

Figure S2. (a)-(c): CVs of varying scan rate from $50 \mathrm{mV} \cdot \mathrm{s}^{-1}$ to $2 \mathrm{~V} \cdot \mathrm{s}^{-1}$. Arrows display

direction of scan starting at $0.4 \mathrm{~V}$ with a vertex potential of $-0.2 \mathrm{~V}$. (d)-(f): Peak oxidative and reductive currents plotted against scan rate. (g)-(i): 100 consecutive scan rates of different indicating the stability of surface functionalization. All CVs plotted using an ITO working electrode and a GNP concentration of $25 \mu \mathrm{g} / \mathrm{mL}$. 


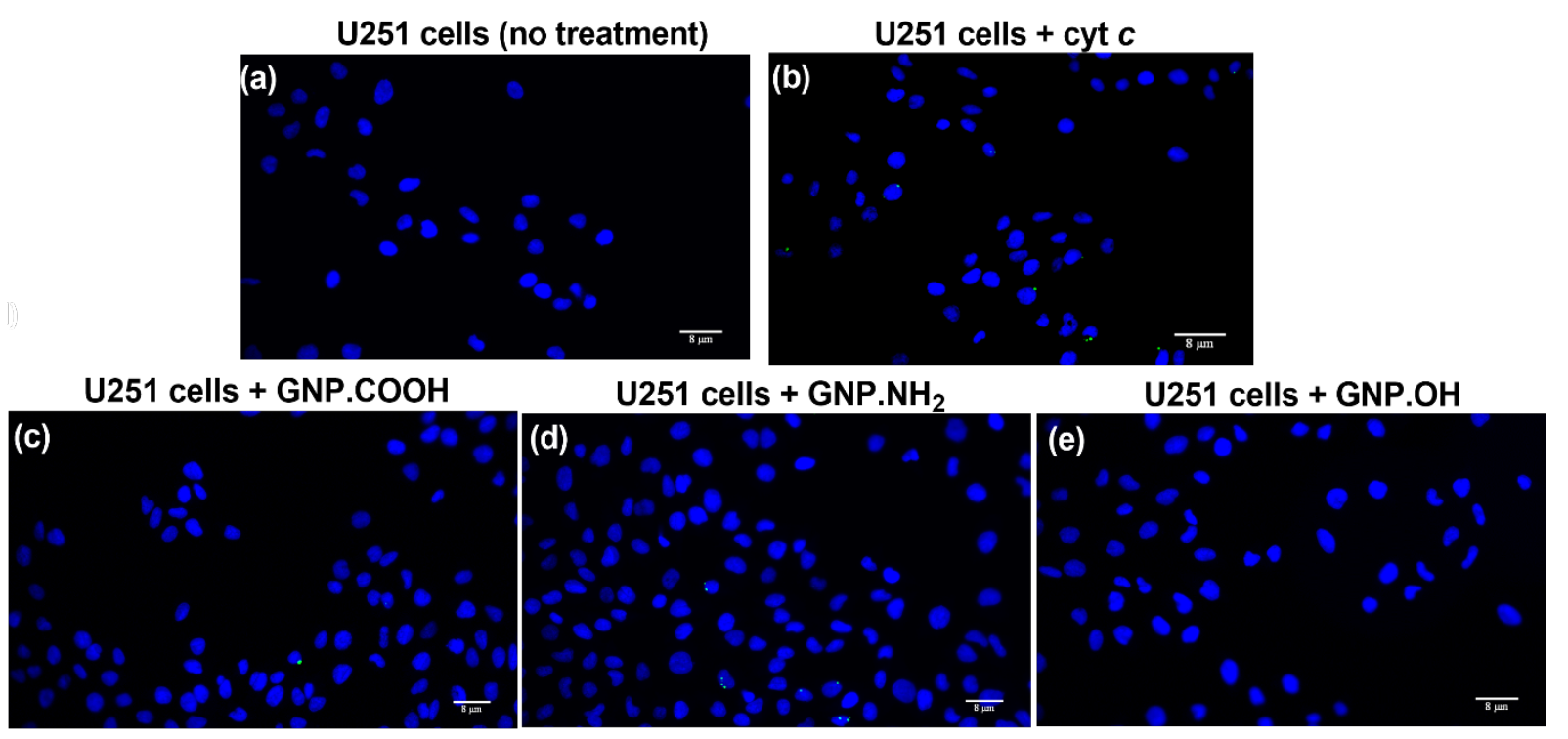

Figure S3. Fluorescent Caspase activity assay. (a-e) Confocal microscopy images of U251 cells incubated with native cyt $c$ and GNPs functionalized with different ligands for $4 \mathrm{~h}$, cells with green fluorescence are Caspase-3/7 positive cells. 


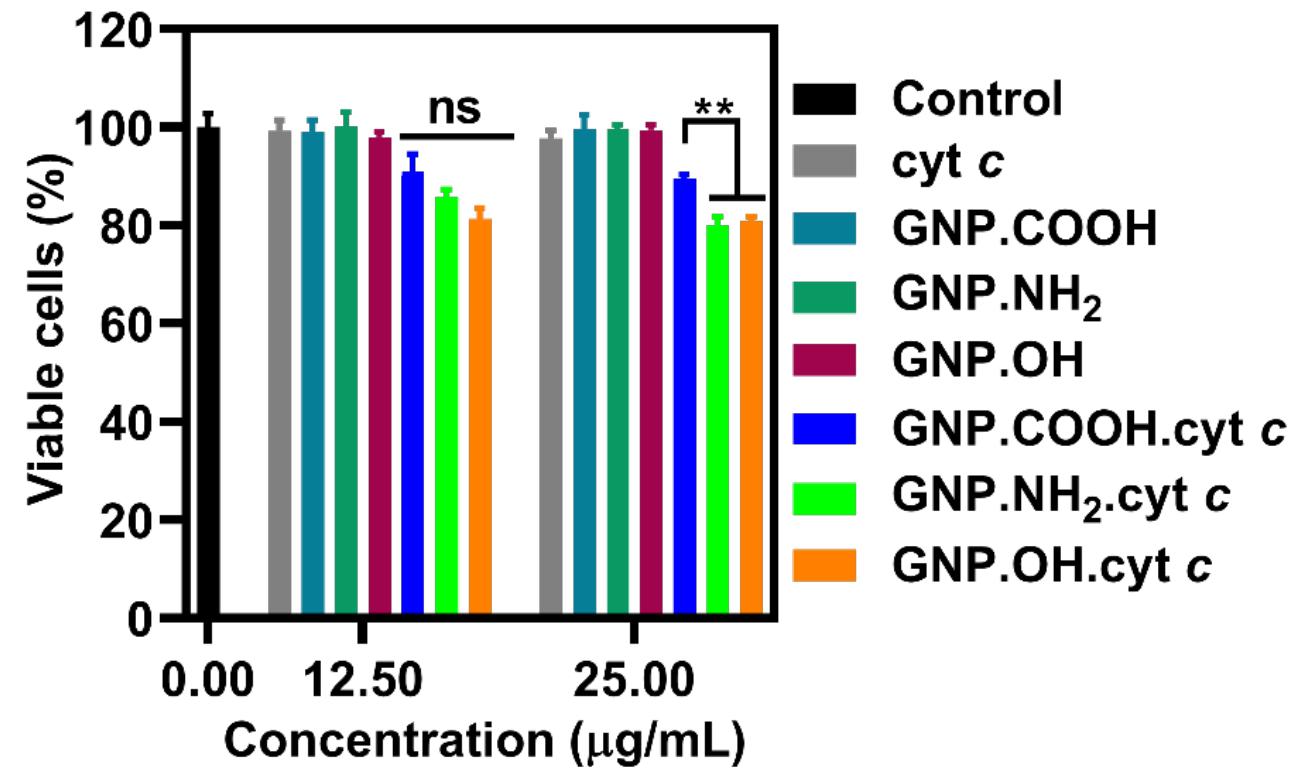

Figure S4. WST-8 metabolic activity assay of U251 cells incubated with different GNP.cyt $c$ conjugates for $4 \mathrm{~h}$. All the experiments were performed in triplicates and the results are expressed as mean \pm S.D. ${ }^{* *} \mathrm{P}<0.01$ vs GNP.COOH.cyt $c$, obtained using 2-way ANOVA with a Tukey post-test. 


\section{References}

[1] R. Michel, S. Pasche, M. Textor, D. G. Castner, Langmuir 2005, 21, 12327.

[2] J. Méndez, M. Morales Cruz, Y. Delgado, C. M. Figueroa, E. A. Orellano, M. Morales, A. Monteagudo, K. Griebenow, Mol. Pharm. 2013, 11, 102.

[3] P. Sanjuan-Alberte, A. Jain, A. J. Shaw, S. A. Abayzeed, R. F. Domínguez, M. E. AleaReyes, M. Clark, M. R. Alexander, R. J. Hague, L. s. Pérez-García, ACS Appl. Nano Mater. 2019, 2 (10), 6397-6408. 